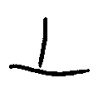

KAPL -1548

Metallurgy and Ceramics (TID-4500, IIth ed)

\author{
General Electric Company \\ KNOLLS ATOMIC POWER LABORATORY \\ Schenectady, New York
}

\title{
SOLUBILITY, DETERMINATION, DIFFUSION AND MECHANICAL EFFECTS OF HYDROGEN IN URANIUM
}

W. D. Davis

August 1, 1956

$\frac{\ell R / \text { Mattine }}{\text { Authorized classifier }}$

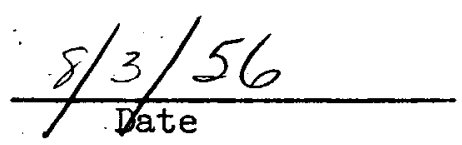

Operated for the

United States Atomic Energy Commission

by the

General Electric Company

Contract No. W-3I-109 Eng-52

UNCLASSIFIED

This document is PUBLICLY RELEASABLE Authorizing Ofincial

Date:

$1-23-07$ 


\section{DISCLAIMER}

This report was prepared as an account of work sponsored by an agency of the United States Government. Neither the United States Government nor any agency Thereof, nor any of their employees, makes any warranty, express or implied, or assumes any legal liability or responsibility for the accuracy, completeness, or usefulness of any information, apparatus, product, or process disclosed, or represents that its use would not infringe privately owned rights. Reference herein to any specific commercial product, process, or service by trade name, trademark, manufacturer, or otherwise does not necessarily constitute or imply its endorsement, recommendation, or favoring by the United States Government or any agency thereof. The views and opinions of authors expressed herein do not necessarily state or reflect those of the United States Government or any agency thereof. 


\section{DISCLAIMER}

Portions of this document may be illegible in electronic image products. Images are produced from the best available original document. 
This report was prepared by General Electric Company in the course of .work under Contract W-31-109 Eng-52, and subject only to the rights of the United States under the provisions of that contract, General Electric Company makes no warranty or representation and shall have no liability with respect to this report or any of its contents or with respect to the use thereof, or with respect to whether any such use will infringe the rights of others.

$* x-*$

This report was prepared as an account of Government sponsored work. Neither the United States, nor the Commission, nor any person acting on behalf of the Commission:

A. Makes any warranty or representation, express or implied, with respect to the accuracy, completeness, or usefulness of the information contained in this report, or that the use of any information, apparatus, method, or process disclosed in this report may not infringe privately owned rights; or

B. Assume any liabilities with respect to the use of, or for damages resulting from the use of any information, apparatus, method, or process disclosed in this report.

As used in the above, "person acting on behalf of the Commission" includes any employee or contractor of the Commission to the extent that such employee or contractor prepares, handles or distributes, or provides access to, any information pursuant to his employment or contract with the Commission. 
$\underline{\text { KAPL }-1548}$

Metallurgy and Ceramics (TID-4500, IIth ed)

Internal Distribution

No. of Copies

AEC, Schenectady Operations Office

1

Anderson, JD

Ahmann, DH

1

Baldwin, EE

1

Cashin, WM

1

Davis, WD

1

Document Library

Haag, RM

Johnston, WV

Smitih, WA, Jr.

Records Storage Center/R Ogilvie

Van Horn, DD

Weber, CE

External Distribution

A. F. Plant Representative, Marietta . 2 Alco Products, Inc. Argonne National Laboratory Armed Services Technical Information Agency, Dayton Arthur D. Little Company

Atomic Energy Commission, Patent Branch

Atomic Energy Commission, Technical Library

Atomics International

Battelle Memorial Institute

Attn: M. W. Mallett

I. I. Marsh

Bettis Plant

Boeing Airplane Company

Brookhaven National Laboratory

Brush Beryllium Company

Bureau of Ships (Code 590)

Chicago Patent Group

Columbia University (Dr. Hassialis)

Combustion Engineering, Inc.

Consolidated Vultee Aircraft Corporation

Convair - General Dynamics Corporation

Dow Chemical: Company, Pittsburg:

Dow Chemical Company, Rocky Flats

duPont Company, Aiken

duPont Company, Wilmington

1

1

4

Frankford Arsenal 
KAPL-1548

External Distribution (continued)

No. of Copies

General Electric Company (ANPP)

General Electric Company, Richland

Attn: R. M. Fryer

L. D. Turner

Goodyear Atomic Corporation

Iowa State College

Kirtland Air Force Base

Lockheed Aircraft Corporation

Los Alamos Scientific Laboratory

Mallinckrodt Chemical Works

Mound Laboratory

National Advisory Committee for Aeronautics, Cleveland

National Bureau of Standards, Atomic Energy Project

National Bureau of Standards (Library)

National Lead Company, Inc., Winchester

National Lead Company of Ohio

Naval Medical Research Institute

Naval Research Iaboratory

New Brunswick Laboratory

New York Operations Office

Nuclear Development Corporation of America

Nuclear Metals, Inc. (Dr. Kaufmann)

Oak Ridge Institute of Nuclear Studies

Oak Ridge National Iaboratory

Office of Naval Research

Phillips Petroleum Company

Princeton University

Sandia Corporation

Signal Corps Center

Sylvania Electric Products, Inc.

Union Carbide Nuclear Company, C-3I Plant

Union Carbide Nuclear Company, K-25 Plant

United Aircraft Corporation

U.S. Geological Survey, Denver

U.S. Geological Survey, MenIo Park

U.S. Geological Survey, Naval Gun Factory

U.S. Geological Survey, Washington

U.S. Naval Postgraduate School

U.S. Naval Radiological Defense Laboratory

U.S. Patent Office

UCLA Medical Research Laboratory

University of California Radiation Laboratory, Berkeley

University of California Radiation Laboratory, Livermore

University of Rochester, Atomic Energy Project

Walter Kidde Nuclear Laboratories, Inc.

Watertown Arsenal

Weil, Dr. George I.

Technical Information Extension, Oak Ridge 
KAPL -1548

CONTENTS

Page

ABSTRACT • • • • • • • • • • • • • • • • • • • • • • •

GENERAL INTRODUCTION • • • . . . . . . . . . . . . . . . . 8

I. SOLUBIIITY OF HYDROGEN IN URANIUM . $\cdot$.

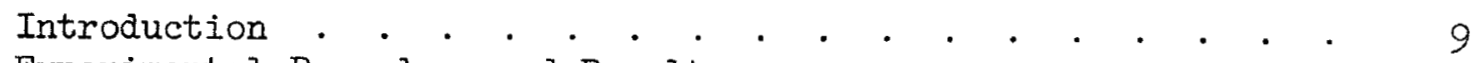

Experimental Procedure and Results. . . . . . . . . . 9

Discussion . . . . . . . . . . . . . . . . . . 22

II. DETERMINATION OF HYDROGEN IN URANIUM . . . . . . . . . . . . . . 27

Introduction . . . . . . . . . . . . . . . . . . 27

Apparatus and Procedure . . . . . . . . . . . . . . 27

Discussion . . . . . . . . . . . . . . . . . . 31

III. DIFFUSION OF HYDROGEN IN URANIUM .

Introduction . . . . . . . . . . . . . . . . . 33

Experimental Procedures and Results . . . . . . . . . 33

Discussion of Results . . . . . . . . . . . . . . 49

IV. EFFECT OF HYDROGEN ON THE DUCTILITY OF URANIUM . . . . . . . . 50

Introduction . . . . . . . . . . . . . . . . . 50

Experimental Procedure and Results . . . . . . . . . . 50

Discussion . . . . . . . . . . . . . . . . . . 54

\section{GRAPHICS}

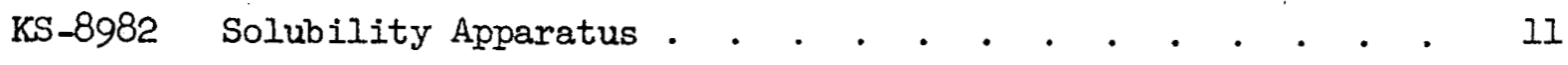

KS-8983 Solubility of $\mathrm{H}_{2}$ in Alpha Uranium . . . . . . . . . 13

$\mathrm{KS}-8984$ Solubility of $\mathrm{H}_{2}$ in $\beta$ and $\gamma-\mathrm{U}$ as a Function of Square Root of Pressure . . . . . . . . . . . 15



$\mathrm{KS}-8986$ : Solubility of $\mathrm{H}_{2}$ in Beta- and Gamma-Phase Uranium as a Function of Temperature . . . . . . . . . . . 19 
KAPL- 1548

Page

KS-8973 Low Pressure Solubility Data . . . . . . . . . . 23

KS-8988 Solubility from Tensile Specimens . . . . . . . . . 25

KS-8972 Apparatus for Determining Hydrogen in Uranium . . . . . 29

KS-9027 Uranium Diffuser No. 1 • • • • • • • • • • • • 35

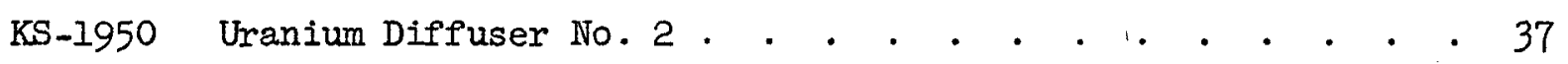

KS-9028 Permeability of Uranium Foil to Hydrogen . . . . . . . 41

KS-9030 Diffusion Constant for Hydrogen in Uranium . . . . . . 43

KS-9037 Diffusion of Hydrogen from Uranium Sphere, $t / \tau$ versus $t$. 47

K-6A5431 Transverse Specimen Cycle Strain Test . . . . . . . . 51

KS-9186 Effect of Hydrogen on Stress - Strain Curve of Uranium . . 55

KS-9189 Ductility of Uranium vs Hydrogen Concentration . • • • 57

KS-9190 Ductility of Uranium vs Hydrogen Concentration . . . . . 59

KS-9191 Ductility of Uranium vs Temperature of Test . . . . . . 61

KS-9192 Ultimate Tensile Strength of Uranium vs Temperature of Test . 63

KS-9193 Grain Structure of Uranium Specimens . . . . . . . . 65 


\section{ABSTRACT}

$\Gamma_{\text {Th }}$ has been determined between 400 and $800^{\circ} \mathrm{C}$ and for pressures up to 1 atmosphere. The solubility in the alpha phase for biscuit uranium shows an anomaly which is believed to be caused by impurities present in the uranium. The analytical method which was used in this investigation is described and evaluated.

A study of the effect of hydrogen concentration and temperature upon the ductility of uranium shows that hydrogen raises the transition temperature of uranium $55^{\circ} \mathrm{C}$. Amounts of hydrogen as low as $0.3 \mathrm{ppm}$ lower the elongation of tensile specimens from 32 to $10 \%$ at room temperature. 
SOLUBILITY, DETERMINATION, DIFFUSION AND MECHANICAL EFFECTS OF HYDROGEN IN URANIUM

W. D. Davis

GENERAL INTRODUCTION

Reactor-grade uranium normally contains 1 to 2 ppm of dissolved hydrogen. The purpose of this investigation was to obtain or extend information on some of the fundamental properties and effects of hydrogen in uranium to enable a better evaluation of the role played by hydrogen in fuel slug fabrication and behavior. 
In several cases, equilibrium was approached from the high-concentration side by lowering the mercury into the burette after the solubility had been determined at a higher pressure. The solubility values which were obtained agreed with those which had been obtained by the normal procedure and showed no trend toward higher values.

It was noticed in all the runs except those at $800^{\circ} \mathrm{C}$ that the amount of gaseous hydrogen in the system continued to decrease slowly after solution equilibrium should have been attained. The rate of decrease, however, was too small to affect seriously the results which were obtained, and no correction was made.

Efforts to determine the cause of the continued loss of hydrogen were not successful. Application of hydrogen pressure to the outside of the uranium vessel did not prevent hydrogen loss; thus the possibility of hydrogen diffusion through the quartz walls was ruled out. The rate of loss increased with temperature, but since the time for equilibrium decreases and the solubility increases with temperature, the relative error was approximately constant. The rate of loss was more nearly proportional to the square root of the pressure than to the first power of the pressure. Upon going into the gamma phase at $800^{\circ} \mathrm{C}$, the rate of loss dropped markedly, which suggests a chemical rather than a physical mechanism for the loss of hydrogen.

Solubilities were determined in the range 400 to $800^{\circ} \mathrm{C}$ and with 60 to $700 \mathrm{~mm}$ mercury pressure. The results of the 58 runs are plotted in KS -8983 and $\mathrm{KS}-8984$.

Figures KS-8985 and KS-8986 compare the solubility values at the oneatmosphere pressure, which were obtained at BMI with those values obtained from Figures KS -8983 and KS-8984 by extrapolation to one-atmosphere pressure. Since only a single point was obtained at $650^{\circ} \mathrm{C}$, the extrapolation to oneatmosphere pressure was made by the assumption that the straight line intersects the ordinate at $0.16 \mathrm{ppm}$ as do the lines for 500 to $600^{\circ} \mathrm{C}$. The KAPL solubility values for the alpha phase appear to agree more closely with those obtained at BMI by the quenching technique than with those values obtained by the absorption method.

Above $500^{\circ} \mathrm{C}$ the heat of solution in the alpha phase appears to have a constant value of $7.9 \mathrm{kcal} / \mathrm{g}$-atom of hydrogen, while below $500^{\circ} \mathrm{C}$ the solubility is higher than that given by extrapolation of the higher-temperature data. This type of behavior is perhaps to be expected for metal-gas solutions when the temperature for compound formation is approached (UH 3 forms at $425^{\circ} \mathrm{C}$ and one atm).

It will be noticed that the solubilities in the alpha phase appear to deviate from the $\sqrt{\mathrm{P}}$ relationship which can be expected for simple interstitial solution of dissociated hydrogen molecules. The straight lines drawn through the points for each temperature all seem to intersect the ordinate above the zero solubility point. 


\section{SOLUBIIIPY OF HYDROGEN IN URANIUM}

\section{INTRODUCTION}

Measurements of the solubility of hydrogen in uranium were first made at the Battelle Memorial Institute (BMI),(CT-818, 1943, Confidential) and covered a range from 470 to $850^{\circ} \mathrm{C}$. The method used was to add a known amount of hydrogen to degassed uranium at the desired temperature, and to measure volumetrically the amount absorbed at equilibrium.

A more recent investigation conducted by Mallett, Trzeciak, and Gerds at BMI, (BMI-985, 1955, Secret) yielded solubility values which were significantly lower than those of the earlier results. The solubility was determined by soaking the uranium specimens in hydrogen under the desired. conditions, quenching these specimens in water to retain the hydrogen, and then analyzing them for hydrogen content by a vacuum-fusion method.

\section{EXPERTMENIAL PROCEDURE AND RESULTS}

The method used for determining the solubility was that of adding known amounts of hydrogen to uranium at the desired temperature, and volumetrically measuring the amount of gas remaining unadsorbed in the system at equilibrium. The apparatus used is shown in Figure KS-8982.

The uranium wire was drawn from pure biscuit uranium. The metal was not analyzed, but it is believed to be at least $99.9 \%$ uranium. A typical analysis of this grade of uranium is as follows: (impurities in ppm)

\begin{tabular}{|c|c|c|c|c|c|c|c|c|c|c|c|c|c|c|}
\hline C & Li & $\mathrm{Be}$ & B & $\mathrm{Na}$ & $\mathrm{M}_{\varepsilon}$ & $\mathrm{Al}$ & $\mathrm{Si}$ & $\mathrm{Ca}$ & $V$ & Cr & $\mathrm{Mn}$ & $\mathrm{Fe}$ & Co & $\mathrm{Ni}$ \\
\hline & & & 2 & & & 20 & 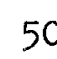 & $<10$ & $<10$ & 7 & 3 & $>100$ & $<5$ & $a$ \\
\hline
\end{tabular}

The normal procedure for a run after the system had been evacuated and the uranium had been sufficiently degassed was as follows. Pure hydrogen gas which had been obtained by diffusion through a hot palladium tube was admitted to both sides of the gas burette. The pressure of the gas was obtained from a Wallace and Tierman diaphragm-type manometer, which is accurate to better than 1-mm mercury. The volume of gas in the calibrated burette was determined to within $\pm 0.01 \mathrm{cc}$ by measuring the height of the right-hand mercury column with a cathetometer. The volume of the burette was approximately $10 \mathrm{ml}$.

After the hydrogen had been isolated by closing stopcock $A$, the hydrogen was admitted to the uranium, the mercury was raised to the top portion of the burette, and the pressure on the left-hand mercury column was adjusted so that the two menisci were equal. Thus, the mercury manometer served merely as a null device while the pressure was read from the diaphragm manometer. Normally, equilibrium was attained by varying the mercury level in the burette at constant pressure. 


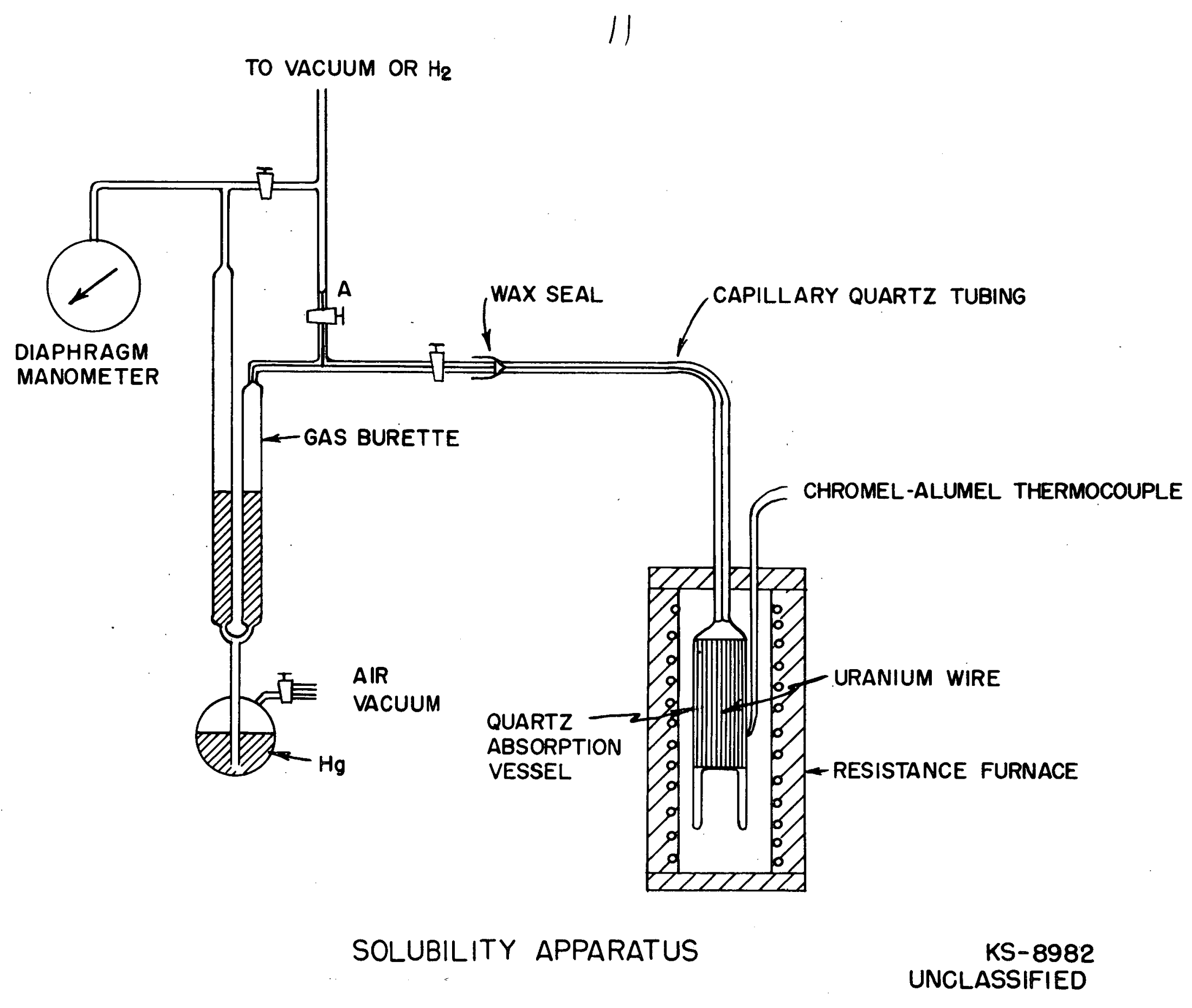




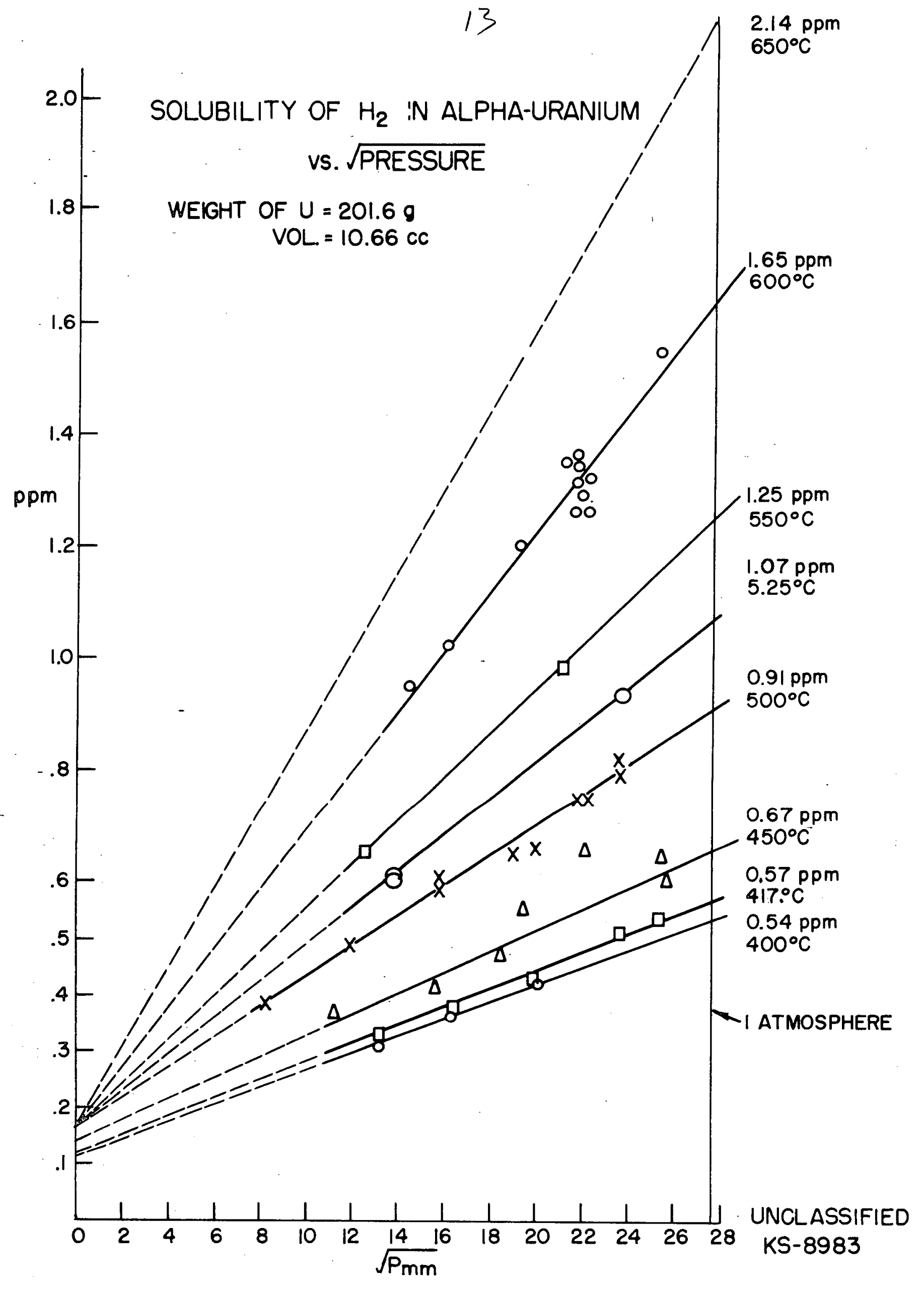




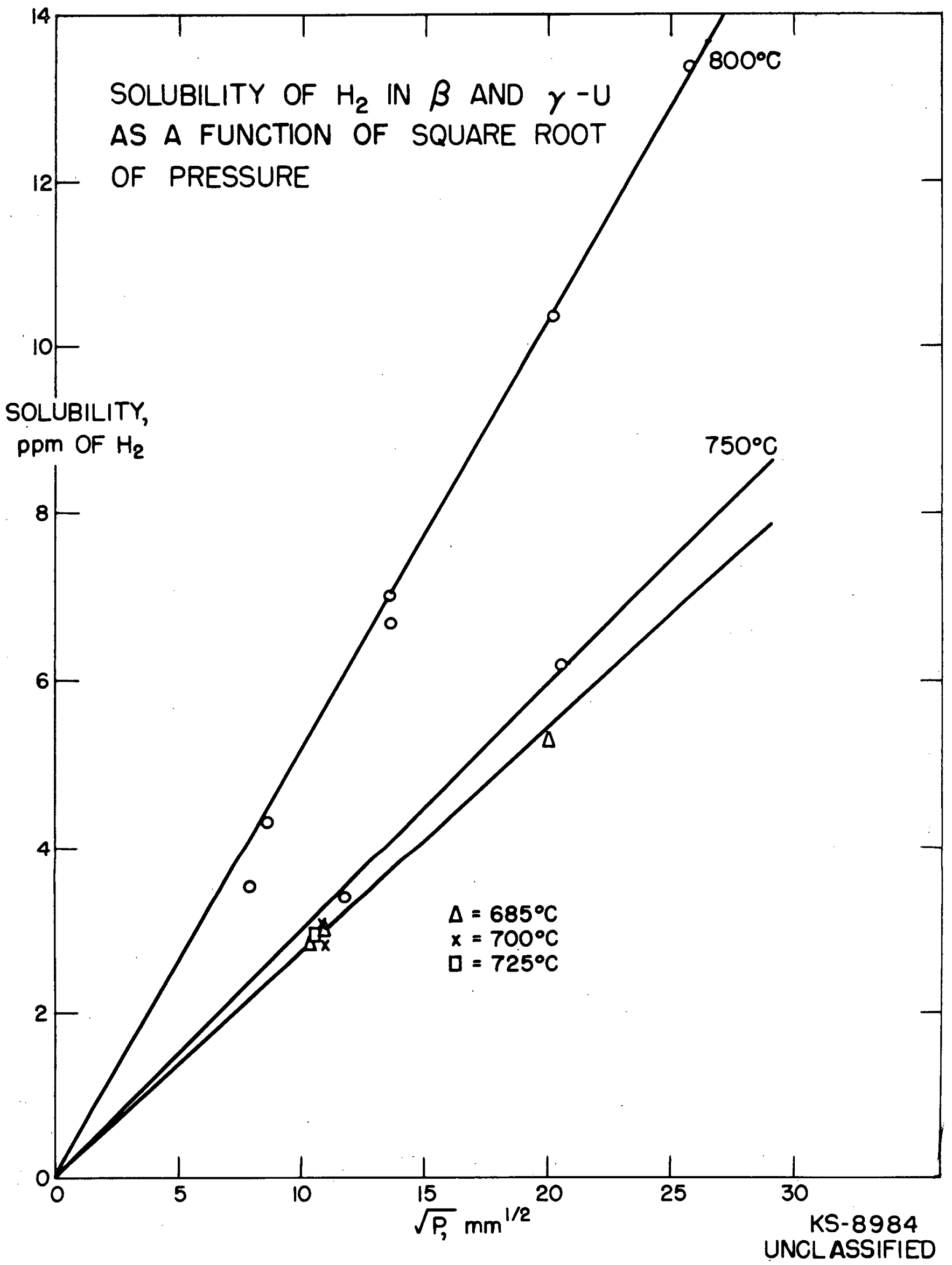




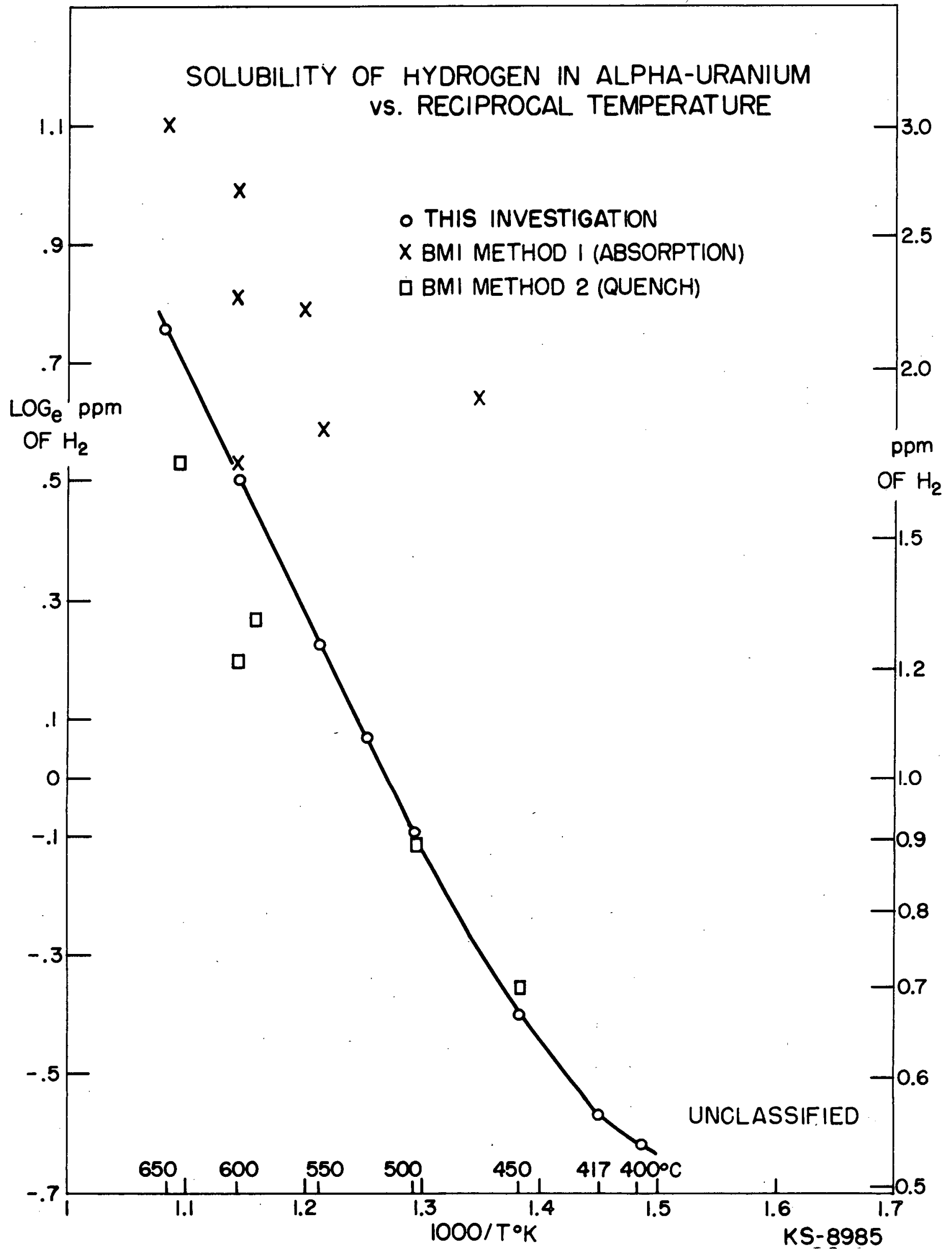




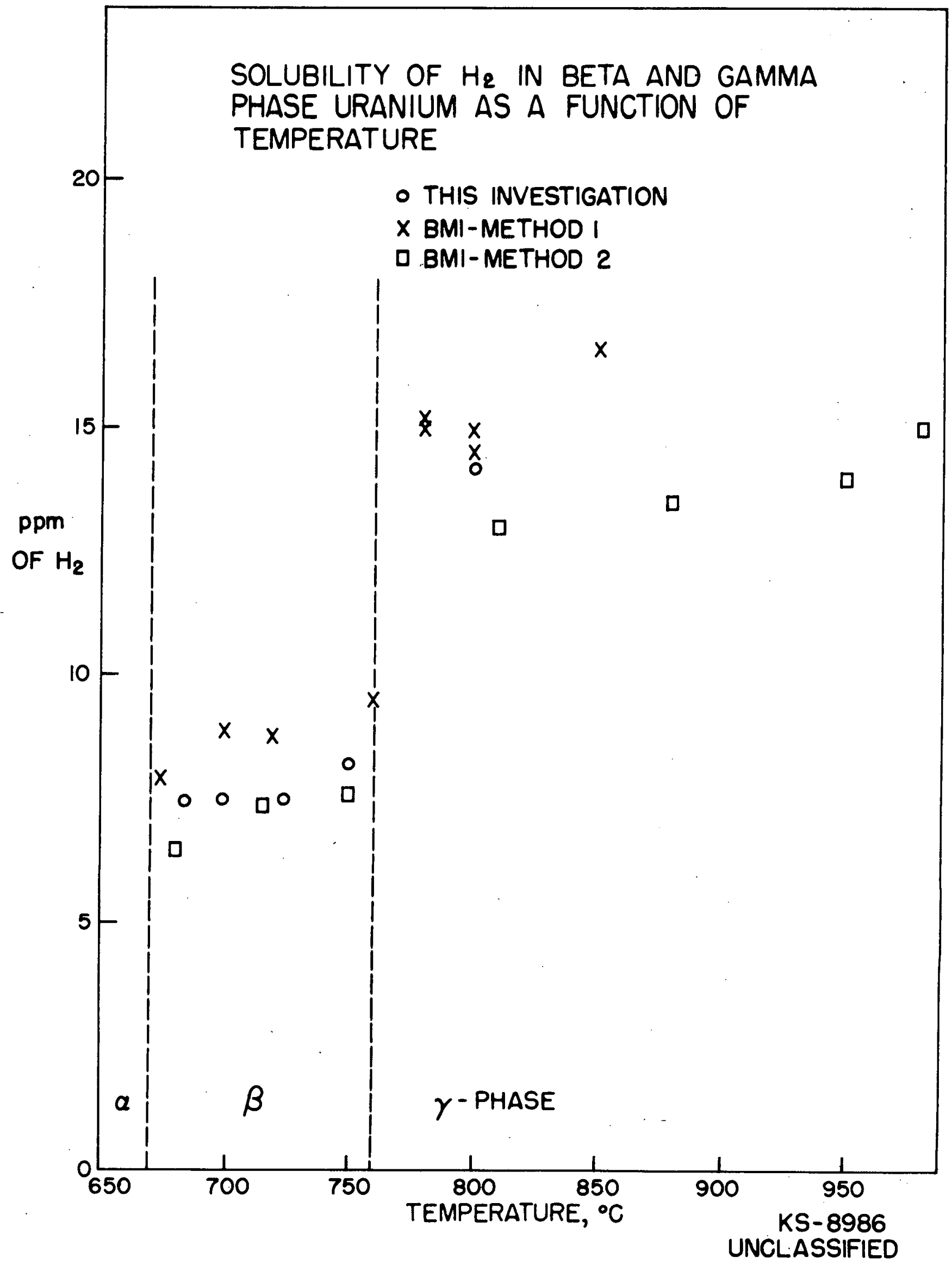


Institute. Spectrographic and chemical analyses of this uranium, in ppm, as reported by BMI were as follows:

$\begin{array}{llllllllllll}\mathrm{Si} & \mathrm{Mo} & \mathrm{Zr} & \mathrm{Fe} & \mathrm{Ni} & \mathrm{AI} & \mathrm{Mn} & \mathrm{Mg} & \mathrm{Ca} & \mathrm{Cu} & \mathrm{C} & \mathrm{N} \\ 150 & 40 & 40 & 20 & 20 & 5 & 5 & 3 & 2 & 2 & 200 & 60\end{array}$

Since this material should be purer than biscuit uranium, two samples were soaked in hydrogen at $600^{\circ} \mathrm{C}$, and then were quenched and were analyzed in the usual manner. The results as shown in $\mathrm{KS}-8973$ indicate an even lower solubility than that exhibited by the previous pure sample. Unfortunately, values of the solubility at lower pressures could not be obtained easily with these small samples, but as can be seen from KS-8973, a straight line drawn through the available points and the origin has approximately the same slope as that line which was obtained on biscuit uranium at high pressure.

\section{DISCUSSION}

The results of the solubility measurements indicate that there is an impurity in the ordinary grade of uranium which, for the first few $\mathrm{mm}$ of hydrogen pressure, causes an abnormally large absorption of hydrogen in alpha uranium. After this impurity is saturated with hydrogen at about 4-mm pressure, the solubility follows the normal $\sqrt{\mathrm{P}}$ dependence with a slope which can be presumed to be characteristic of pure uranium. This behavior suggests that the impurity is not in the solution but that it exists as a separate phase. On the assumption that the impurity combines with an approximately equal number of hydrogen atoms, the concentration of the impurity need be only about 0.002 atom per cent, or for an element with an atomic weight of the order of 100, about $10 \mathrm{ppm}$. The actual impurity cannot be determined without performing more careful analyses for trace amounts of hydride forming elements. The fact that the beta and gamma phases exhibit normal solubility behavior indicates that either the impurity has gone into solution in the uranium or that the hydride phase has become unstable at these temperatures.

It is unfortunate that a more thorough and careful investigation of these interesting phenomena could not be made. Measurements of solubilities at high and low pressures and at various temperatures for both ordinary purity uranium and pure uranium should be made in order to understand this system more fully. 
To eliminate the possibility that this unusual behavior was caused by experimental error, the solubility at low pressures and at $600^{\circ} \mathrm{C}$ for this grade of uranium was determined approximately by two independent means.

The first and most precise method was similar to the high-pressure method. A slab of uranium about $3 / 8$ inch thick weighing 73 grams was placed in a quartz tube furnace. After degassing, known amounts of hydrogen were admitted to the system, and the amount of hydrogen unadsorbed was measured at equilibrium. Pressures were measured with a Mcleod gauge which had a range of $2.7 \mathrm{~mm}$. The apparatus had been designed for analysis of uranium for hydrogen, and because of its large ratio of free volume to uranium volume, the results which were obtained by this apparatus were not so precise as the high-pressure results. However, as shown in KS-8973, the measurements show definitely that the solubility does rise very rapidly with pressure for the first 1 or $2 \mathrm{~mm}$ before settling down to normal behavior.

The second method involves the soaking of uranium in hydrogen at the desired temperature and pressure, quenching with a stream of helium, and analyzing the sample for hydrogen. The samples which were used weighed 50 to 70 grams. In addition to these special runs, several tensile specimens of uranium that had been heated in hydrogen at $600^{\circ} \mathrm{C}$ at various pressures and which had been quenched wexe analyzed for hydrogen. Since these samples weighed about 15 grams, the solubility values were probably less reliable. However, the agreement with the larger samples was satisfactory. The results which were obtained by this method are shown in KS-8973 and KS-8988, and confirm the other solubility values.

A check of the solubility at $700^{\circ} \mathrm{C}$ and at pressures below $1 \mathrm{~mm}$ by use of the first method agreed very well with the extrapolated high-pressure values. If there is any abnormal solubility at $700^{\circ} \mathrm{C}$, it must be below $0.01 \mathrm{ppm}$.

In order to check the possibility that the unexpected behavior at low pressures could be caused by an impurity in the uranium, an especially purified sample of uranium was obtained. The analysis of this sample, in ppm, was as follows:

$\begin{array}{ccccccccccccccccc}\text { Al } & \mathrm{B} & \mathrm{Be} & \mathrm{C} & \mathrm{Ca} & \mathrm{Co} & \mathrm{Cr} & \mathrm{Cu} & \mathrm{Cd} & \mathrm{Fe} & \mathrm{Li} & \mathrm{Mg} & \mathrm{Mn} & \mathrm{Na} & \mathrm{Ni} & \mathrm{Si} & \mathrm{V} \\ 5.0 & <0.2 & <0.02 & 65 & 40 & <1.0 & 16 & 20 & <0.2 & 80 & <0.2 & 12 & 8 & <1 & 20 & 35 & 0.8\end{array}$

The solubility of hydrogen in this uranium was determined by directabsorption measurements only. The results as shown in KS-8973 clearly indicate less solubility for the purer grade of uranium.

A small amount of center-cut ingot uranium was available as a result of a cooperative hydroze analysis program sponsored by the Battelle Memorial 


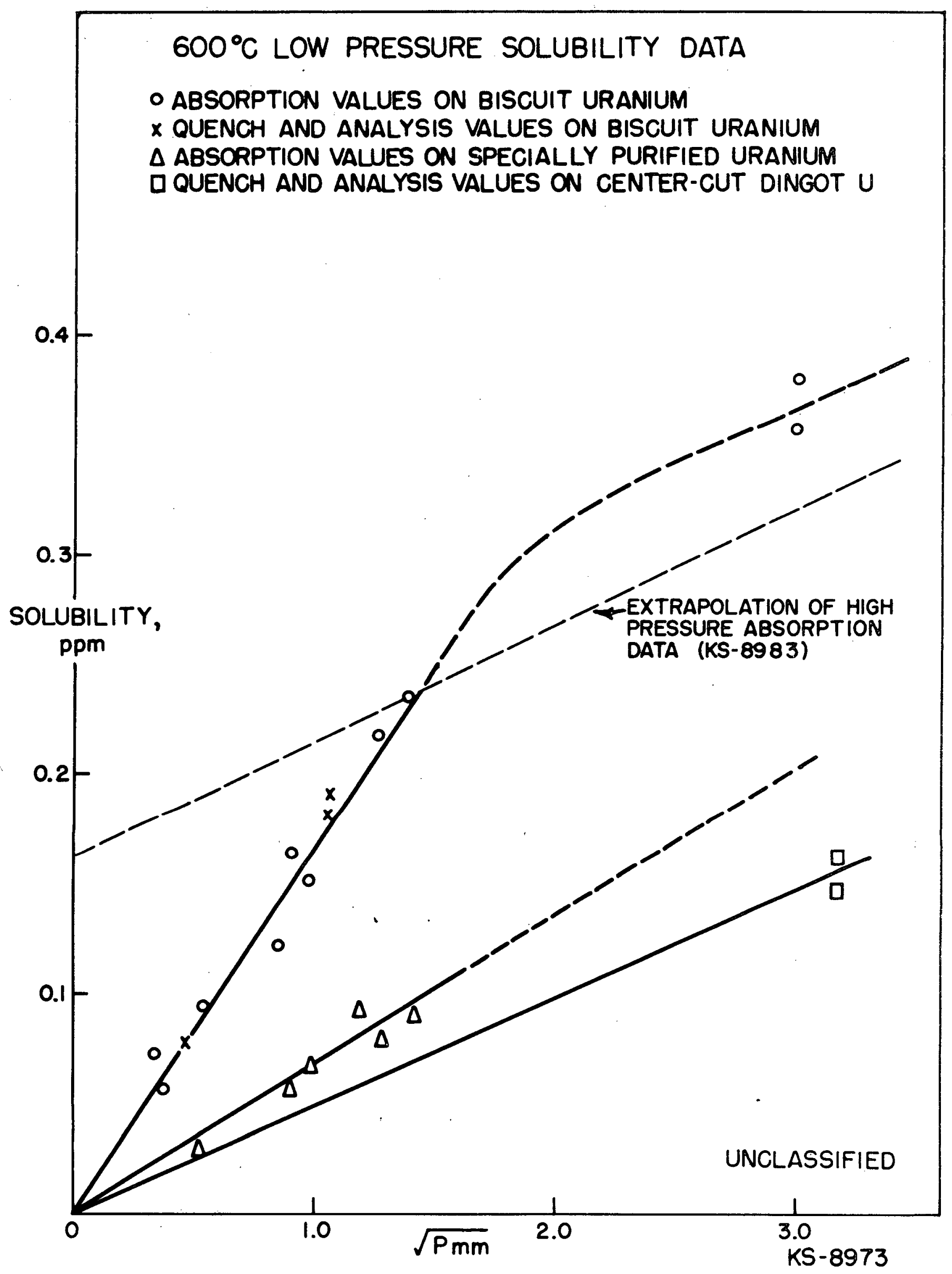









\section{DETERMINATION OF HYDROGEN IN URANIUM}

\section{INTRODUCTION}

Analysis of uranium for hydrogen appears to have been developed first in experiments at Battelle Memorial Institute. (BMI) (CI-753, CI-893, 1943, Confidential) The samples weighing about 400 to $800 \mathrm{~g}$ were inductively heated to $750^{\circ} \mathrm{C}$ in a vacuum system. The evolved gas was pumped into a measuring volume. Analysis of the gas showed it to be almost 100\% hydrogen. The disadvantage of this method was that there was a continued evolution of hydrogen from the uranium, and hence a relatively large correction had to be applied to the results.

A superior method was finally developed at BMI which eliminated this correction. The sample was heated in a resistance furnace to only $575^{\circ} \mathrm{C}$ in a small closed system, and the pressure rise was measured with a mercury manometer. Equilibrium was established in 6 to 20 hours, after which no further pressure rise was found. The maximum error was found to vary from about $20 \%$ at $0.5 \mathrm{ppm}$ to $5 \%$ at $15 \mathrm{ppm}$.

Variations of these early procedures and other methods involving vacuum fusion or combustion have been investigated at several laboratories, including KAPL, in the last few years. (BMT-X-128, Secret)

The procedure described in this report was developed for the analysis of small. samples weighing 5 to $10 \mathrm{~g}$ with a hydrogen concentration as low as $0.1 \mathrm{ppm}$. In most cases, an accuracy of a few per cent was considered adequate.

\section{APPARATUS AND PROCEDURE}

The final form of the apparatus used for the determination of the amount of hydrogen in uranium is shown in KS-8972. The standard taper joints were sealed with Apiezon $\mathrm{W}$ wax.

Before the sample was introduced into the quartz tube it was rinsed with benzene to remove grease. If heavily oxidized, the sample was also abraded or sectioned on a cut-off wheel before the benzene rinse.

First the sample was placed just below the entrance joint, and the system was thoroughly evacuated for at least two hours to a pressure of about 10-5 mm. Just before the actual analysis, the quartz tube was outgassed by heating it to 700 to $800^{\circ} \mathrm{C}$ with a torch. The sample was then either tapped down to the end of the quartz tube or pushed down by means of a magnet and a small piece of iron inserted with the sample. liquid nitrogen was then applied to the trap, and after the system was isolated from the vacuum pumps, the sample was heated to $600^{\circ} \mathrm{C}$. Equilibrium pressure was reached in about 1 hour for small samples (about $10 \mathrm{~g}$ ) and within two hours for larger samples (about $50 \mathrm{~g}$ ). 
The rate of pressure rise after equilibrium was established was usually negligible, and no correction was made for it. When the pressure rise exceeded the range of the Mcleod gauge, an evacuated 2-liter bulb was added to the volume of the collection system. Since the 2-liter bulb also reduced the correction for the amount of hydrogen remaining in the uranium, it should be used if the pressure exceeds about $1 \mathrm{~mm}$.

For samples of low hydrogen content, a blank should be determined. This may be done by pumping all the hydrogen from the sample at $600^{\circ} \mathrm{C}$ after the analysis is complete. The sample is then removed, exposed to the atmosphere for about one hour, and re-analyzed. Before a liquid nitrogen trap was added to the furnace tube, the blank usually was more than 0.02 cc of hydrogen and was quite erratic. With the use of a liquid nitrogen trap, as shown in $\mathrm{KS}-8972$, the blank was reduced to about $0.010 \mathrm{cc}$ of hydrogen, or $0.020 \mathrm{cc} / \mathrm{cc}$ for a $10-\mathrm{g}$ sample, and was much more reproducible. Supposedly, the liquid nitrogen trap removes water vapor and hydrocarbons that react with the uranium to form hydrogen.

In the early stages of the development of this method, the gas evolved was analyzed by admitting the gas to a hot palladium tube. 'The hydrogen content of the gas could be estimated from the drop in pressure caused by diffusion of hydrogen through the palladium. In all cases, at least 98 to $99 \%$ of the gas was hydrogen; hence, no correction was applied for any nonhydrogen content.

Calculation of the hydrogen content from the observed pressure rise is straightforward except that the amount of hydrogen remaining in the uranium must be estimated from the solubility curves shown in Figure KS-8973 of Section $I$. The upper curve was obtained for biscuit uranium, which is the grade of uranium used in other investigations of the uranium-hydrogen system. The lower curves were obtained for two special grades of uranium containing fewer impurities and inclusions. Fortunately, the amount of hydrogen remaining in solution is usually much less than that evolved from the sample, especially if the 2-liter bulb is included in the system. However, for greatest accuracy at low concentrations, the solubility curve which is applicable to the grade of uranium being analyzed should be known. This curve may be determined by absorption measurements in the same apparatus, or more easily, by re-analyzing the same sample after completion of the regular analysis. Alternatively, the final pressure and hence the amount of dissolved hydrogen may be reduced by closing off the furnace tube from the rest of the system after the initial rapid evolution of hydrogen, pumping away the known amount of hydrogen that has collected in the Mcleod gauge, collection bulb, and connecting lines, and then proceeding with the analysis in the usual manner by reopening the stopcock to the furnace.

For final pressures less than $2000 \mu$, the solubility for biscuit uranium is given by:

$$
\begin{gathered}
S=0.038 \sqrt{\mathrm{P}_{m m}} \text { or } 0.0012 \sqrt{\mathrm{P}_{\mu}} \\
S \text { in } \frac{\operatorname{cc~of~} \mathrm{H}_{2}}{\operatorname{cc~of} \mathrm{U}}
\end{gathered}
$$




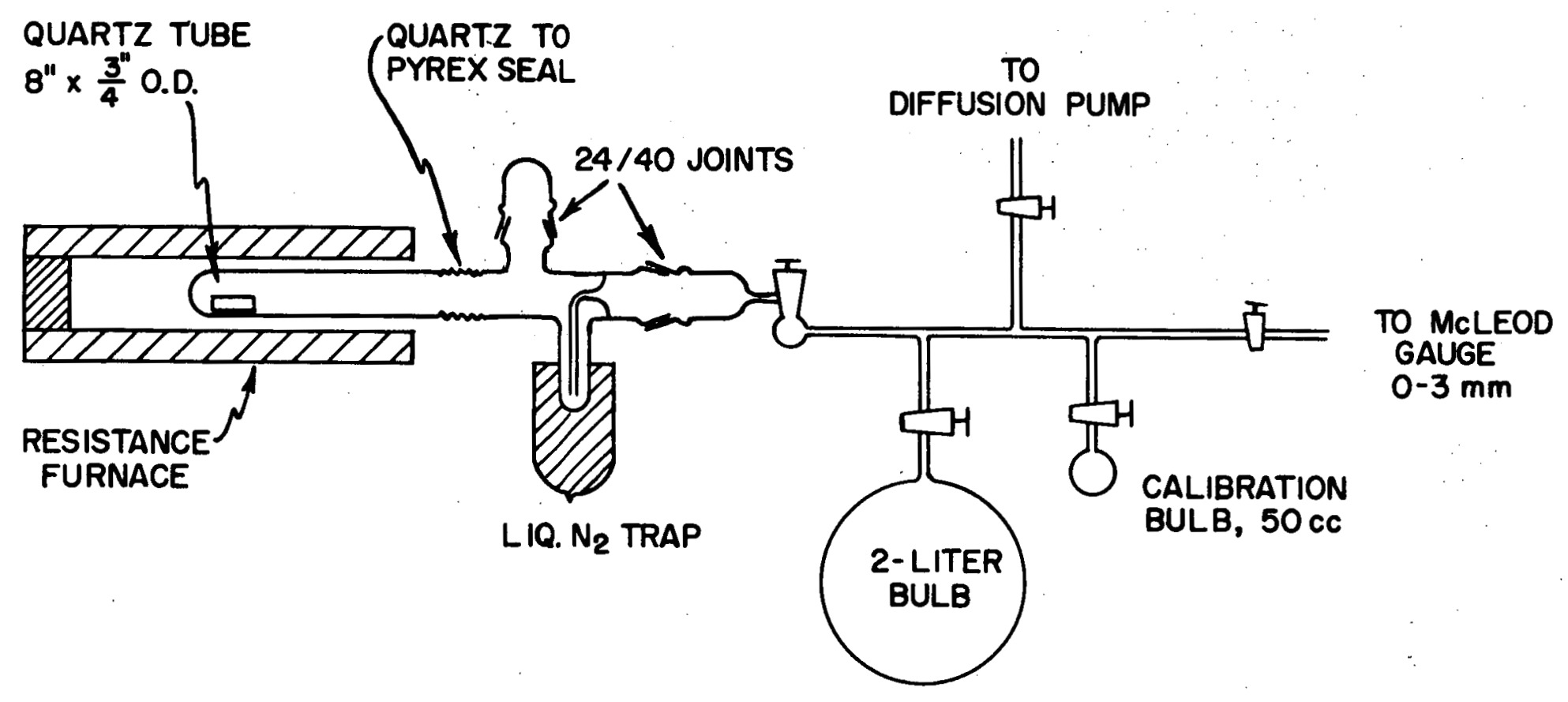

APPARATUS FOR DETERMINING HYDROGEN IN URANIUM 

by:

With this relationship, the hydrogen content of the sample is given

$$
\frac{\text { cc of } \mathrm{H}_{2}(\mathrm{INI})}{\operatorname{cc} \text { of } \mathrm{U}}=0.0012 \sqrt{\mathrm{P}}+2.49 \times 10^{-5} \quad \frac{\mathrm{PV}}{\mathrm{W}}-0.020=\frac{\mathrm{ppm}}{4.36}
$$

with $\mathrm{P}$ in microns, $\mathrm{V}$ in cubic centimeters, and $\mathrm{W}$, the sample weight, in grams.

The blank value of 0.020 probably varies somewhat with the system used and the sample weight. For the greatest accuracy in measuring low concentration samples, the blank value should be determined on the same piece of uranium after completion of the analysis.

DISCUSSION

The precision or random errors associated with the analysis have been estimated as follows.

The volume of the system is calibrated by the small bulb with the furnace at $600^{\circ} \mathrm{C}$ and the trap cold. The error in the total volume, excluding the 2-liter bulb of about $370 \mathrm{cc}$, is about 1 to $2 \%$. The error in the pressure reading is about $1 \%$ at the higher pressures and 2 to $3 \%$ at the lower ranges $(100 \mu)$. Hence, the error for a sample of high hydrogen content is estimated to be no more than about $3 \%$ and is probably somewhat less.

For samples of very low hydrogen content, the main source of error is the blank. The blank appears to be consistent to at least $+0.005 \mathrm{cc} / \mathrm{cc}$, and perhaps as low as $+0.001 \mathrm{cc} / \mathrm{cc}$ for a $10 \mathrm{~g}$ sample. Thus $\bar{s}$, the over-all error for a $0.01 \mathrm{cc} / \mathrm{cc}^{-}$sample is estimated to be 5 to $10 \%$.

Table I shows the results obtained for samples which either had an approximately known composition or had a duplicate sample with the same composition (the latter are indicated by using the same number but different letters). The known samples were prepared by soaking them in hydrogen at $600^{\circ} \mathrm{C}$ with a measured pressure of hydrogen until equilibrium had been established; they were then quenched by flowing helium. Some hydrogen was lost during quenching but this amount was small, at least for the large samples. The error in the amount of hydrogen predicted for the sample represents only the estimated error in the solubility values.

Samples 4 through 10 were tensile specimens which were analyzed after fracture. Since they were exposed to the atmosphere for several days, the poor agreement obtained in some cases may not have been the fault of the analysis itself. The large samples were analyzed immediately after heat treatment, and good agreement with the predicted value was obtained. 
Samples 11, 12, and 13 were obtained from BMI in their cooperative analysis program. Duplicates of these samples were analyzed by various other laboratories to ascertain the reliability of the various methods and techniques for analyzing uranium for hydrogen. (BMI-X-128, Secret)

The over-all precision shown by duplicate samples is approximately that which was estimated from the separate errors. Samples $I I A$ and $I I B$ were run before the liquid nitrogen trap improvement was in use. These results show poorer agreement than the other duplicates.

\section{TABLE I}

\section{TYPICAL DETERMINATIONS}

\begin{tabular}{|c|c|c|c|}
\hline Sample No. & Sample Weight & \multicolumn{2}{|c|}{$\frac{\text { cc of Hydrogen/cc of Uranium }}{\text { Actual }}$} \\
\hline 1 & 58 & 0.018 & $0.018 \pm 0.002$ \\
\hline $\begin{array}{l}2 A \\
2 B\end{array}$ & $\begin{array}{l}73 \\
58\end{array}$ & $\begin{array}{l}0.042 \\
0.044\end{array}$ & $\begin{array}{l}0.040 \pm 0.002 \\
0.040 \pm 0.002\end{array}$ \\
\hline $\begin{array}{l}3 A \\
3 B\end{array}$ & $\begin{array}{l}73 \\
58\end{array}$ & $\begin{array}{l}0.082 \\
0.087\end{array}$ & $\begin{array}{l}0.080 \pm 0.005 \\
0.080 \pm 0.005\end{array}$ \\
\hline 4 & 15 & 0.055 & $0.037 \pm 0.002$ \\
\hline 5 & 15 & 0.063 & $0.065 \pm 0.005$ \\
\hline 6 & 15 & 0.089 & $0.080 \pm 0.005$ \\
\hline 7 & 15 & 0.150 & $0.125 \pm 0.005$ \\
\hline 8 & 15 & 0.18 & 0.21 \\
\hline 9 & 15 & 0.27 & 0.29 \\
\hline 10 & 15 & 0.37 & 0.37 \\
\hline $\begin{array}{l}11 \mathrm{~A} \\
11 \mathrm{~B}\end{array}$ & $\begin{array}{l}8 \\
8\end{array}$ & $\begin{array}{l}0.94 \\
1.01\end{array}$ & \\
\hline $\begin{array}{l}12 \mathrm{~A} \\
12 \mathrm{~B}\end{array}$ & $\begin{array}{l}10 \\
10\end{array}$ & $\begin{array}{l}0.065 \\
0.063\end{array}$ & \\
\hline $\begin{array}{l}13 \mathrm{~A} \\
13 \mathrm{~B}\end{array}$ & $\begin{array}{l}10 \\
10\end{array}$ & $\begin{array}{l}1.38 \\
1 \cdot 33\end{array}$ & \\
\hline
\end{tabular}


III. DIFFUSION OF HYDROGEN IN URANIUM

INTRODUCTION

In 1943, workers at Battelle Memorial Institute (BMI) (CT-1009, 1943, Confidential) determined the diffusion coefficient at 566 and $593^{\circ} \mathrm{C}$ from rates of outgassing of uranium slugs charged with hydrogen. Because of the paucity of these data and the need for calculating rates of migration of hydrogen in uranium, the diffusion coefficient for this system was determined from 500 to $900^{\circ} \mathrm{C}$ by experiments at KAPL.

Two independent methods were used for determining the diffusion coefficient. Method 1 consisted of measuring rates of evolution from $1 / 2-i n .-$ diam uranium spheres charged with hydrogen, and Method 2 consisted of measuring the rate of passage of hydrogen through uranium diaphragms. The agreement between the two methods was satisfactory.

Concurrent with this investigation, the results obtained at BMI were extended by using degassing rate data. (BMI-985 and BMI-972, Secret)

EXPERIMENTAL PROCEDURES AND RESUTTS

Method 1

The steady-state permeability of a membrane is expressed by the following equation:

$$
J=\frac{A D}{d}\left(C_{1}-C_{2}\right)
$$

where

$$
\begin{aligned}
& J=\text { permeability (amount of gas penetrating per unit time) } \\
& A=\text { area of membrane } \\
& d=\text { thickness of membrane }
\end{aligned}
$$

$c_{1}=$ concentration of gas in metal just below front, or entering, surface

$\mathrm{C}_{2}=$ concentration of gas in metal just below back, or exit, surface.

If there are no rate-limiting surface steps, $C_{1}$ or $C_{2}$ will be the equilibrium solubility for the pressure on the front or back surface, $P_{1}$ or $\mathrm{P}_{2}$, respectively. For most metals and a diatomic gas, the equilibrium solubility is proportional to the square root of the pressure, giving the equation:

$$
J=\frac{A D}{d} K\left(\sqrt{P_{1}}-\sqrt{P_{2}}\right)
$$

where $K$ is the solubility constant. 
If $\mathrm{P}_{2}$ is zero, $\mathrm{J}$ will be proportional to $\sqrt{\mathrm{P}_{1}}$ and

$$
\mathrm{DK}=\frac{J \mathrm{~d}}{\mathrm{~A} \sqrt{\mathrm{P}_{I}}}=J_{\mathrm{O}} \text { (specific permeability) }
$$

Hence, measurements of $J_{0}$ together with values for $\mathrm{K}$ will yield the diffusion coefficient.

Two membranes were used in this investigation. The first was prepared by vacuum brazing a 0.27 -mm-thick uranium foil to a small copper cylinder with silver solder as shown in KS-9027. The hydrogen enters the quartz furnace tube enclosing the assembly and diffuses through the uranium into the copper cylinder.

This diffuser has several disadvantages:

1. Hydrogen diffusing through the copper adds to the observed permeability.

2. The area of the membrane cannot be accurately known because some of the brazing material flows out onto the uranium.

3. The thickness of the uranium was insufficient to prevent marked deformation of the membrane, thus increasing the uncertainty in the area and thickness. A leak which developed in the membrane before the measurements were complete probably'was caused by the deformation.

The second membrane was machined from a solid cylinder of uranium and had a liameter of $2.68 \mathrm{~cm}$ and a thickness of $0.612 \mathrm{~mm}$. The membrane was brazed into a copper cylinder as shown in KS-1950. The entire unit was placed in a large VYCOR tube which was continuously evacuated to prevent oxidation of the copper.

Initially, the permeabilities were determined by measuring the rate of pressure rise in a known volume connected to the exit side of the membrane. By using a micromanometer manufactured by the Consolidated Engineering Corporation rates could be determined accurately in about $100 \mathrm{sec}$ with less than $100-\mu$ pressure rise. Later determinations were made by measuring the pressure drop across a glass constriction inserted between the membrane and the vacuum system. The constriction was calibrated by comparison with the first method, and also by measuring the rate of pressure decrease in a bulb which was being evacuated through the constriction. The two calibration methods agreed within about $1 \%$ and showed that the pressure drop across the constriction was nearly linear with flow rate. The advantage of this second method is that permeability is measured continuously, and the approach to steady-state conditions can be observed easily. 


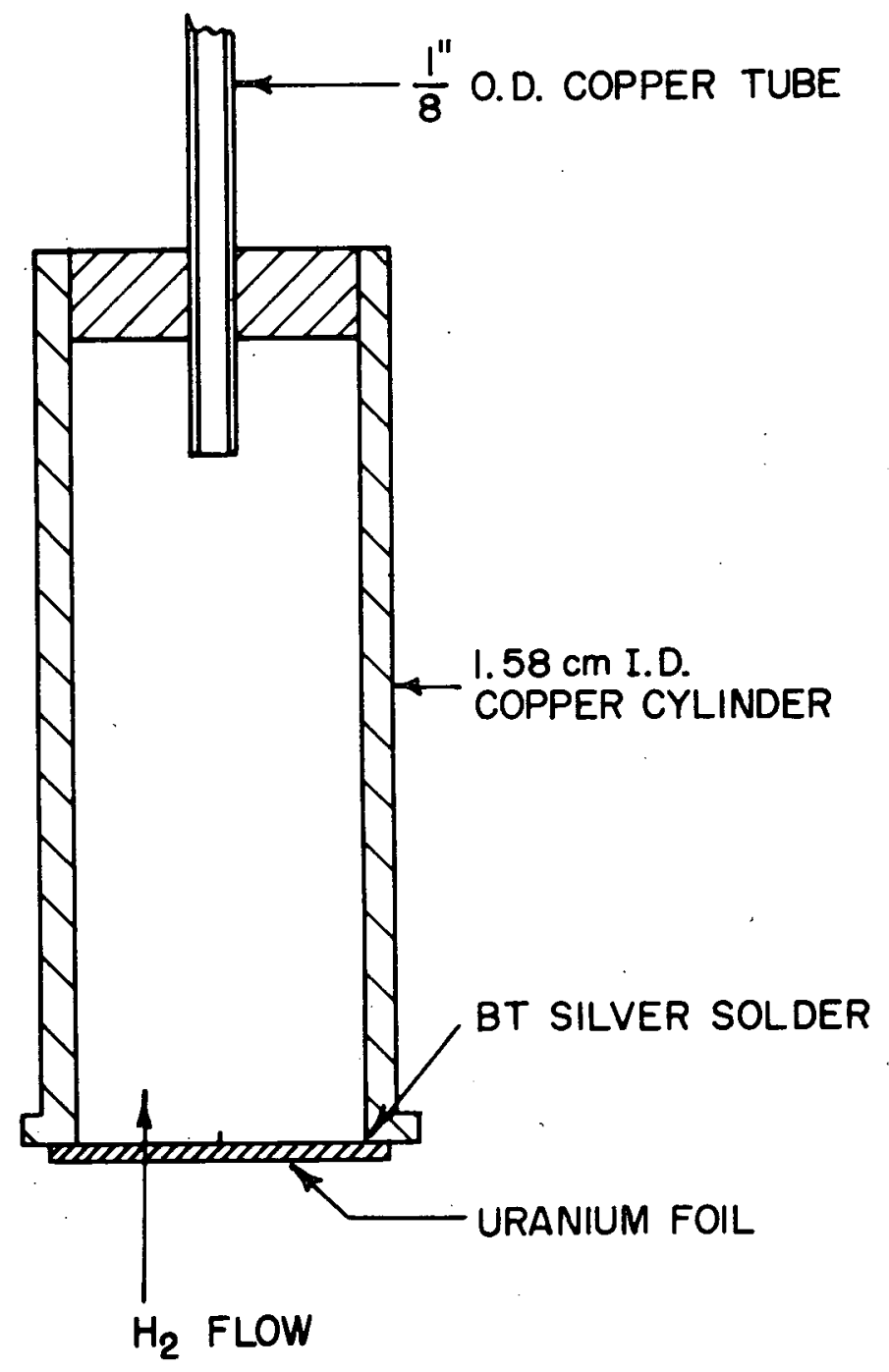

URANIUM DIFFUSER NO.I

\author{
KS-9027 \\ UNCLASSIFIED
}




\section{7}

URANIUM DIFFUSER NO. 2

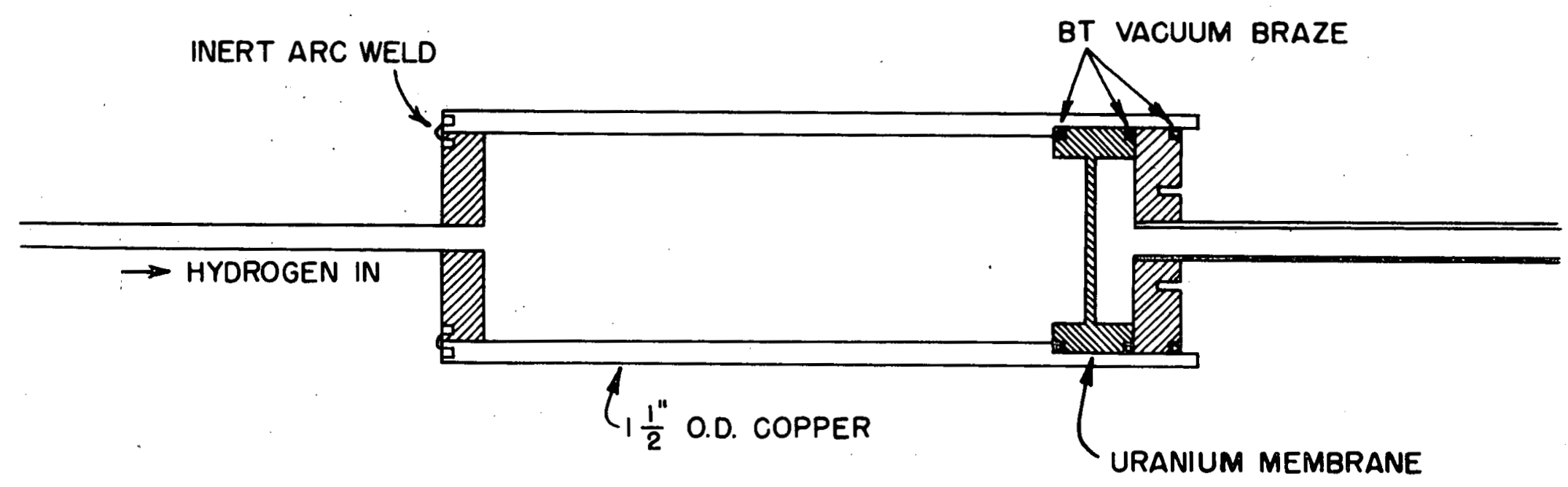

UNCLASSIFIED

KS -1950 
It was found that the permeability of uranium membranes to hydrogen was not constant but that it varied considerably with time and prior treatment. Exposure to hydrogen at operating temperatures usually caused a slow increase in the permeability, but occasionally the permeability would decrease. Prolonged evacuation either slowly decreased the permeability or had no effect. Phase changes increased the permeability.

Some typical curves of the permeability at $500^{\circ} \mathrm{C}$ versus $\sqrt{\mathrm{P}}$ for the first membrane are shown in KS-9028. Curve No. I was obtained immediately after heating the foil to $500^{\circ} \mathrm{C}$ for the first time. Overnight exposure to flowing hydrogen raised the permeability, as shown in Curve No. 2. A few hours of additional exposure yielded the results shown in Curve No. 3. The uranium was then heated into the beta phase and back to $500^{\circ} \mathrm{C}$ in about 1 houx. This gave the maximum permeability, shown by Curve No. 4. Overnight exposure to hydrogen again decreased the permeability to that shown in Curve No. 5. These and other runs demonstrate that the permeability is very easily influenced by previous treatment, and care must be taken to achieve maximum values.

The behavior shown by uranium has all the earmarks of surface poisoning. Similar curves obtained in an investigation of the permeability of palladium to hyarrogen (KAPL-1375, April 1955) were caused by surface contamination. impeding the flow of hydrogen across the interface. The contamination in the case of uranium is probably an oxide or nitride of uranium. Fydrogen treatment either chemically removes the contamination or provides an inert atmosphere while the contamination is removed by:

1. diffusion into the uranium,

2. reduction by the carbon present in the uranium.

The beneficial effect of phase changes probably is caused by cracking of the impervious layer by contraction or expansion of the uranium surface, which exposes a fresh, clean surface to the hydrogen.

The solubility of hydrogen in alpha uranium of the purity used in this investigation does not follow the $\sqrt{\mathrm{P}}$ law (see Section $I$ ). However, the fact that the maximum permeability in the alpha phase appears to be proportional to $\sqrt{\mathrm{P}}$ indicates that the concentration gradient established across the cleanest uranium still is not the one calculated from the equilibrium solubility curve and the hydrogen pressures on the two sides. Apparently, the slight surface impedance still present on the back'surface together with the small back pressure necessary for permeability measurements is sufficient to increase the back concentration, $\mathrm{C}_{2}$, from the expected value of less than $0.001 \mathrm{cc} / \mathrm{cc}$ to a value near to the "knee" of the solubility curve. Hence, for purposes of calculating the diffusion coefficient of alpha uranium, $\mathrm{C}_{2}$ is assumed to be constant at about $0.036 \mathrm{cc}$ of hydrogen per cc of uranium, and $K$ is the slope of the high-pressure portion of the solubility curve. The solubility of hydrogen in beta- or gamma-phase uranium follows the $\sqrt{P}$ law exactly enough so that $\mathrm{C}_{2}$ can be assumed equal to zero. 
The following table lists the observed specific permeabilities $\left(1 \mathrm{~cm}^{2}\right.$ area, 1-cm thickness, at I-atm pressure) and the calculated diffusion constants. The usual plot of $\log D$ versus $I / T$ is included in KS-9030.

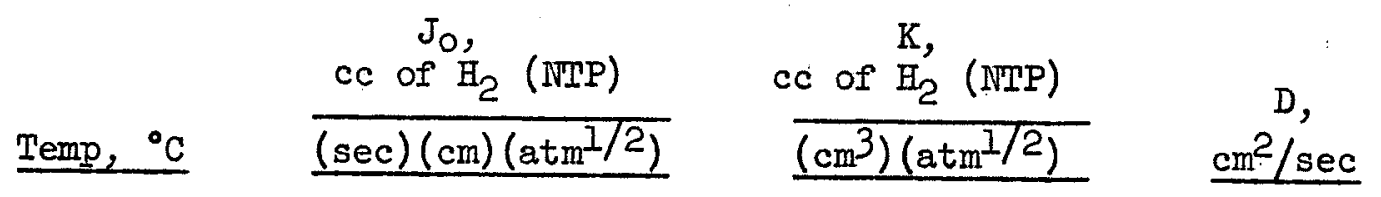

\begin{tabular}{llll}
\multicolumn{2}{c}{ Foil No. 1} \\
500 & $3.2 \times 10^{-6}$ & 0.172 & $1.86 \times 10^{-5}$ \\
600 & $11.7 \times 10^{-6}$ & 0.343 & $3.44 \times 10^{-5}$
\end{tabular}

Foil No. 2

$\begin{array}{llll}450 & 2.01 \times 10^{-6} & 0.118 & 1.71\end{array}$

$475 \quad 2.60 \times 10^{-6} \quad 0.143 \quad 1.82$

$\begin{array}{llll}500 & 3.92 & 0.172 & 2.28\end{array}$

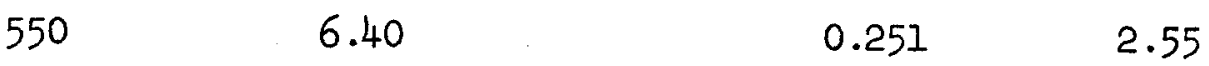

$\begin{array}{llll}600 & 12.8 & 0.343 & 3.73\end{array}$

$\begin{array}{llll}650 & 18.9 & 0.454 & 4.17\end{array}$

$\begin{array}{llll}680 & 64.0 & 1.71 & 3.75\end{array}$

Method 2

The rate of evolution of gas from a sphere with a uniform initial concentration into a vacuum (concentration of gas in metal at surface $=0$ ) is governed by the following equation:*

$$
A=A_{0}\left[1-\frac{6}{\pi^{2}} \sum_{n=1}^{\infty} \frac{1}{n^{2}} e^{-n^{2} t / \tau}\right]
$$

*Carslaw, H. S. and Jaeger, J. C., Conduction of Heat in Solids. Oxford University Press, 1948, p. 201. 
41

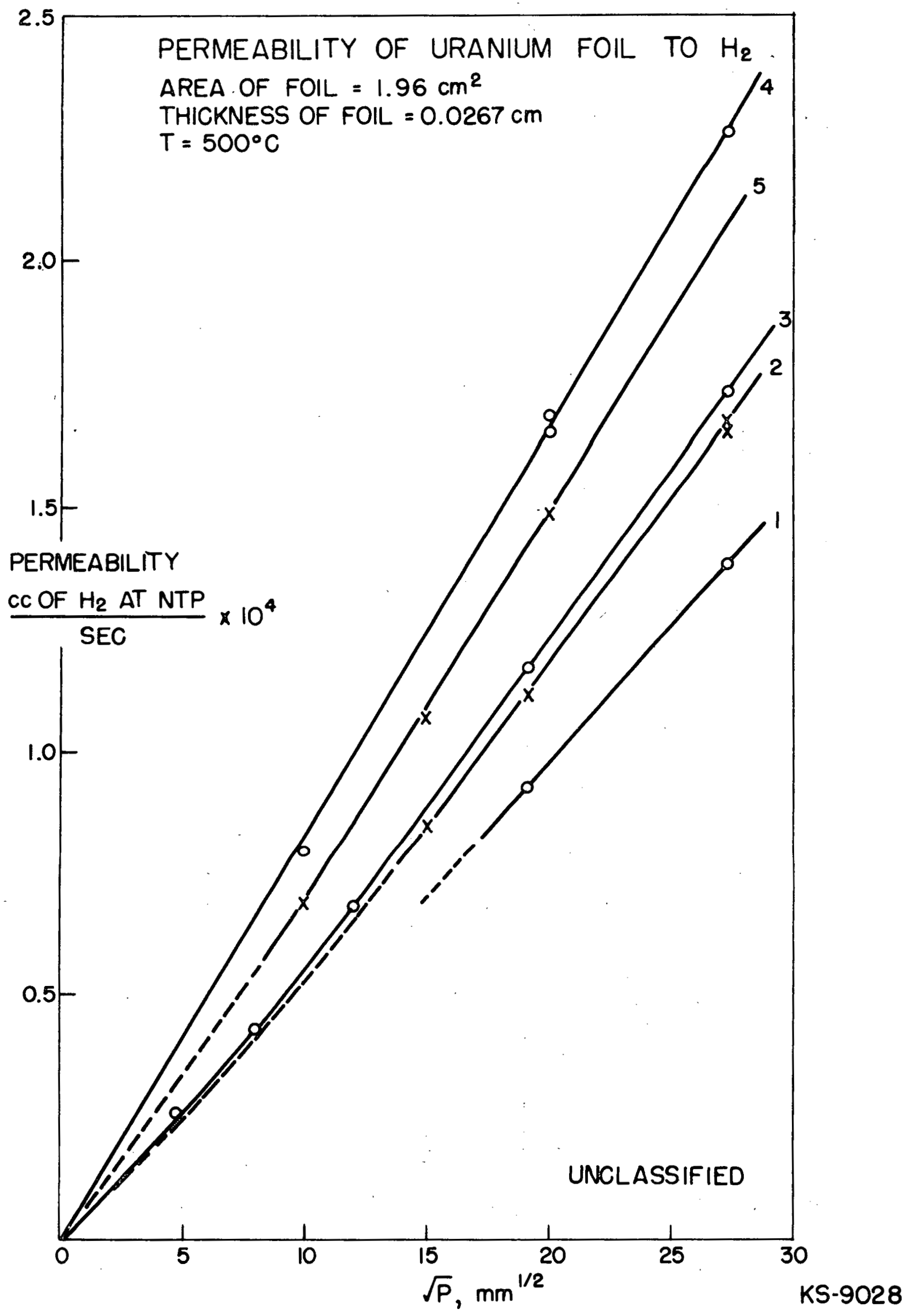




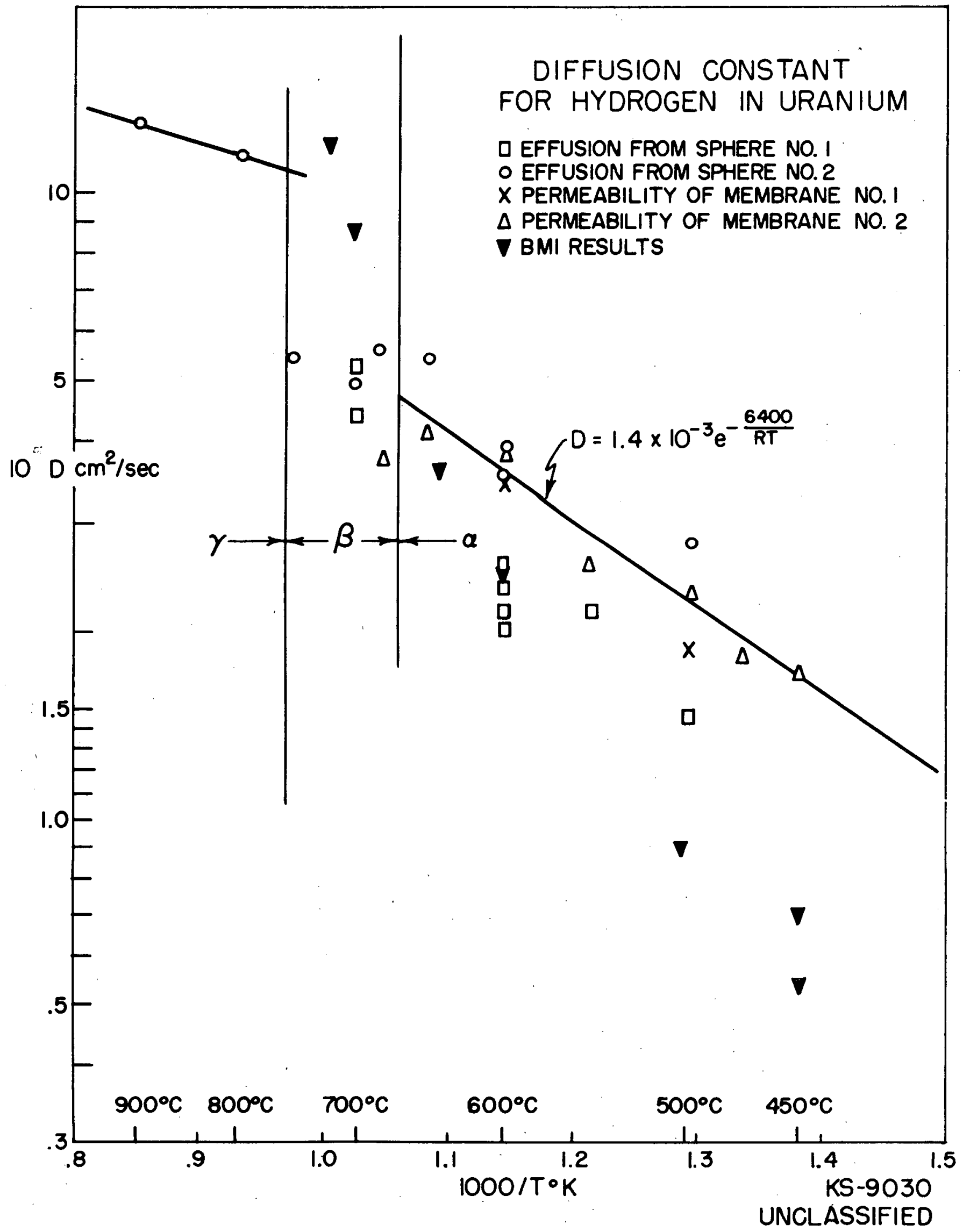


where

$$
\begin{aligned}
A & =\text { total amount of gas evolved at time } t \\
A_{0} & =\text { initial amount of gas in solid } \\
D & =\text { diffusion coefficient } \\
r & =\text { radius of sphere } \\
\frac{I}{\tau} & =\frac{\pi^{2} D}{r^{2}}
\end{aligned}
$$

$D$ may be evaluated by measuring the fraction of the gas evolved from the sphere as a function of time.

The procedure used to determine $D$ was to heat a $1 / 2$-in.-diam uranium ball in an atmosphere of hydrogen until equilibrium had been established. At $t$ ime $t=0$, the hydrogen atmosphere was removed with a diffusion pump at a rate rapid enough that the diffusion of hydrogen from the sphere could be assumed to be unimpeded by back pressure. When the pressure had been reduced to a negligible amount (usually in one or two minutes), the pumping was discontinued and the effusing gas was collected in a known volume. By measuring the pressure of the gas, the quantity of hydrogen that evolved. from the sphere after pumping was discontinued could be determined as a function of time.

By making the collection volume large ( 1 1/2 to 3 liters), the pressure of hydrogen on the sphere during effusion was kept low enough that Equation (4) could be expected to apply. In fact, for most of the runs, the hydrogen was allowed to flow into the large collection volume only until about $150 \mu$ of pressure had been attained. After the pressure was measured, this portion of the gas was pumped away and collection of gas was resumed. During the final stages of evolution, the pressure was kept considerably below $100 \mu$ in order to desorb all the hyorogen in the uranium.

In the early stages of the investigation, pressures were measured with a McLeod gauge. For the later, more accurate runs, a micromanometer manufactured by the Consolidated Engineering Corporation was used, which enabled pressures to be measured more rapidly and accurately.

Two methods can be used to calculate $D$ from the measured quantities. The most convenient and accurate method depends upon knowledge of the amount of gas evolved between $t=0$ and the time pumping was discontinued. (so that A may be calculated). This quantity can be evaluated by subtracting the total amount of hydrogen collected from the total amount originally dissolved at $t=0$, as determined from the solubility measurements shown in Section $I$. By adding this value to the amount of hydrogen actually collected up to time, $t$, the value of $A$ at $t$ is determined. 
Given $A_{0}$ and $A$, values of $t / \tau$ can be read easily from a graph of $A / A_{0}$ versus $t / \tau$ prepared from Equation (1). A graph of $t / \tau$ versus $t$ should then yield a straight line of slope $1 / \tau$, from which $D$ may be calculated easily.

The best value of $A_{0}$ to be used for runs on alpha uranium is not equal to the initial amount of hydrogen, as would be expected. The gas pressure at the surface of the uranium usually was not quite zero, and some surface impedance probably was always present. As suggested by the results of the permeability study on uranium membranes, both these factors tend to raise the surface concentration up to about $0.036 \mathrm{cc} / \mathrm{cc}$ during the early stages of evolution, thus lowering the effective concentration gradient by this amount.

Figure KS -9037 shows a run calculated on the assumption that the surface concentration was zero $\left(A_{0}=\right.$ equilibrium solubility), and on the alternative assumption that the surface concentration was $0.036 \mathrm{cc} / \mathrm{cc}$.

( $A_{0}=$ equilibrium solubility - 0.036.) The points lie closer to a straight line by use of the second assumption. The upward curvature of the line for this case probably is due to the fact that in the later stages of a run, the concentration in the sphere does decrease toward zero, giving erroneous high values for $t / \tau$. In addition, the value of $t / \tau$ becomes increasingly sensitive to small errors in $A / A_{0}$ as $A / A_{0}$ approaches 1 . For this reason, not much weight should be given to values of $t / \tau$ above about 1.0 .

Ruas in the beta and gamma region of uranium, where the solubility obeys the $\sqrt{\mathrm{P}}$ law and the surface concentration can be assumed to be zero, gave very good straight lines up to $t / \tau=1.0$ and, in some cases, very much higher. An excellent mun obtained at $700^{\circ} \mathrm{C}$ is included in $\mathrm{KS}-9037$.

In the second method for calculating $D$, neither $A$ nor $A_{0}$ need to be known. A value of $\tau$ is assumed, and from the graph of $A / A_{0}$ versus $t / \tau$ a value of $A / A_{O}$ is obtained for each measured value of $t$. A plot of the measured amounts of gas collected at these values of $t$ against the corresponding calculated values of $\mathrm{A} / \mathrm{A}_{\mathrm{O}}$ then should yield a straight line if the correct value of $\tau$ has been chosen. The best value of $\tau$ is determined by a trial and error method. Besides being tedious, this method suffers from a lack of sensitivity to variations in $\tau$, and it was finally discarded in favor of the first method.

One of the major concerns in these experiments was the problem of obtaining and maintaining a clean surface on the uranium. The uranium was pickled in $\mathrm{HNO}_{3}$ and washed with water and acetone just before insertion into the furnace tube. The furnace tube itself had no grease or wax joints and was connected to the rest of the system by a U-tube immersed in liquid nitrogen. At $600^{\circ} \mathrm{C}$, the first run gave high values of $D$, but subsequent runs showed that the apparent $D$ was decreasing steadily. Apparently, the uranium surface was being contaminated by the usual impurities coming off the heated glass surfaces. A small leak that developed at this time drastically reduced the evolution rate, confirming that surface contamination was indeed the cause for low values of $\mathrm{D}$. 
47

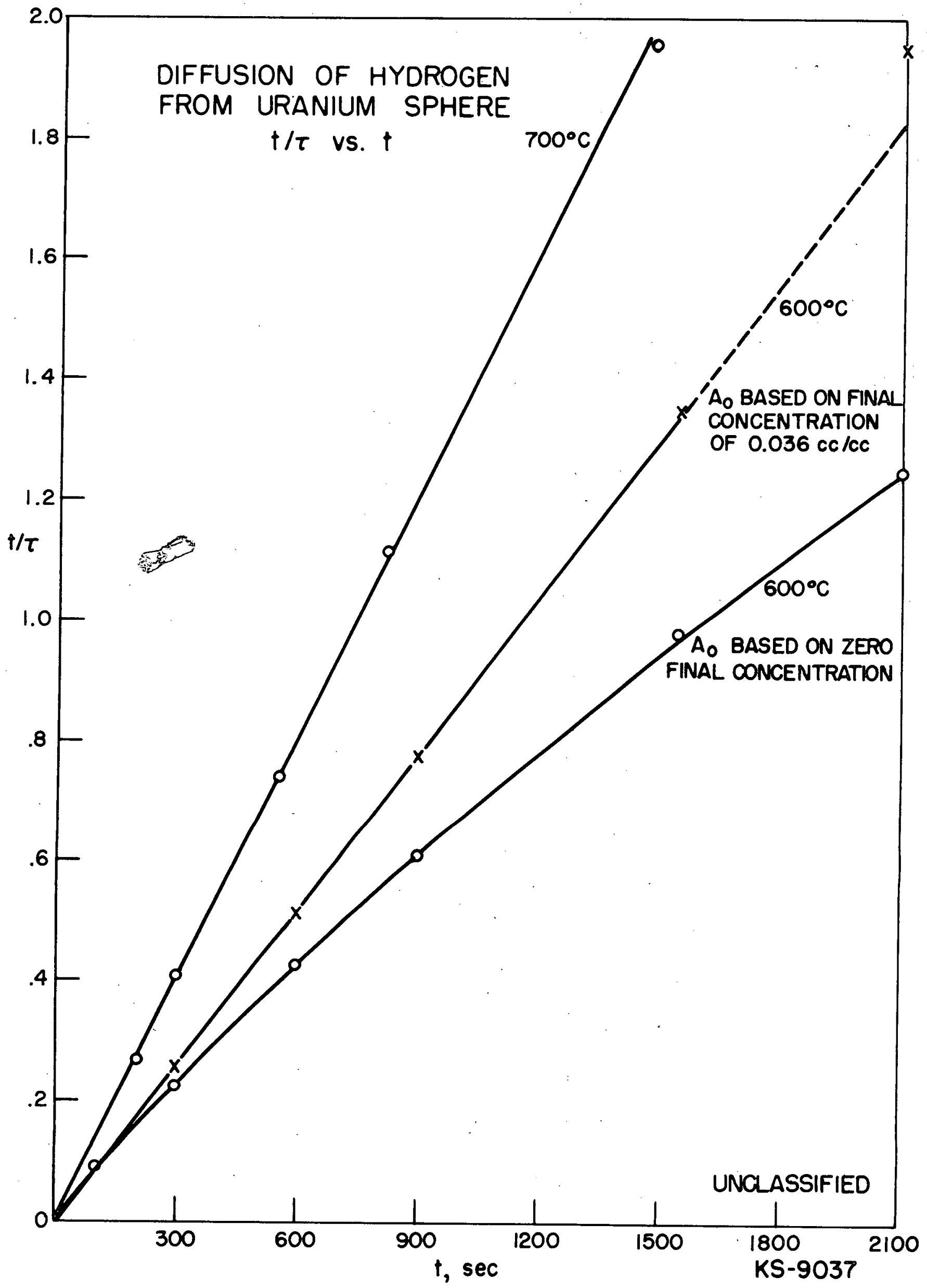


Attempts to clean the uranium surface by heating it to $900^{\circ} \mathrm{C}$ in vacuum or hydrogen were not successful. Repeated cycling across the alpha-beta transition temperature made a considerable improvement, but failed to return the uranium to its initial condition. The best method proved to be the formation of hydride on the uranium surface. If a very small amount of hydrogen is allowed to react with the uranium surface at about $300^{\circ} \mathrm{C}$, the oxide or nitride film apparently is broken sufficiently that it no longer impedes the flow of hydrogen. After this treatment, the value of $D$ at $600^{\circ} \mathrm{C}$ was approximately the same as that obtained on first heating the uranium. Subsequent hydriding treatments appeared to make no further improvement. The system was now sufficiently clean and outgassed so that D did not decrease with time.

\section{DISCUSSION OF RESULTS}

The agreement between the two different methods and four samples of uranium, as shown in KS-9030, is satisfactory in view of the difficulty experienced in eliminating surface effects. The relatively large amount of scatter in the data is not caused by errors in measurement but by variations in surface conditions. The high values obtained toward the end of the series of runs on the second sphere are likely to be the most accurate values because of the greater care taken to clean the uranium surface. The most inaccurate values are judged to be those taken from the first sphere, because no effort was made to activate the uranium surface, and in addition, the actual measurements were less precise than in the other series. The permeability values on the first membrane probably are low because insufficient time was available to activate the surface of the uranium before it ruptured. A clean surface is especially important in the case of thin membranes because of the fact that the effect of a small surface impedance becomes relatively more important as the volume impedance with which it is in series is decreased.

Satisfactory agreement with BMI values is obtained only in the high alpha range. Surface contamination could have caused the low values at 450 and $500^{\circ} \mathrm{C}$, but the fact that the BMI values in the beta range are about twice as high as those obtained at KAPL suggests that there is some other source for the discrepancy.

Unfortunately, the scatter in the data and the limited temperature range for each phase make any estimate of the activation energy for diffusion in each phase and the corresponding value for $D_{0}$ very inaccurate. The lines drawn for the alpha and gamma phases in KS-9030 are only reasonable estimates of the true values. Accordingly, comparison of these results with theoretical deductions would probably not be meaningful and no attempt was made to do so. The values which were obtained for the alpha phase-$1.4 \times 10^{-3} \mathrm{~cm}^{2} / \mathrm{sec}$ for $D_{0}$ and $6.4 \mathrm{kcal} / \mathrm{g}$-atom for the activation energy-are reasonable values for these quantities, however. 


\section{EFFECT OF HYDROGEN ON THE DUCTILITY OF URANIUM}

\section{INTRODUCTION}

Small amounts of dissolved hydrogen have been found to decrease the ductility of many metals. As ordinary reactor-grade uranium contains appreciable amounts of hydrogen, it is important to assess the effect of this hydrogen on the ductility of the uranium.

Workers at Los Alamos Scientific Laboratory found that the medium chosen for annealing uranium had considerable effect on the mechanical properties of the uranium, (IA-1619, August 1, 1953). Any medium other than a good vacuum or a purified helium atmosphere lowered the room temperature properties of ultimate strength, hardness, and elongation. Annealing in a hydrogen atmosphere or in a carbonate salt bath produced the greatest decrease in elongation. Gas analysis of the uranium indicated that dissolved hydrogen was the principal cause of the low physical property values.

A study recently completed at Battelle Memorial Institute (BMI-980, February 14, 1955) showed that alpha uranium undergoes a tensile transition from a slip-type failure to a semicleavage-type fracture in the vicinity of room temperature. An increase in hydrogen content from 0.3 to $4.7 \mathrm{ppm}$ appreciably reduced the reduction in area at fracture and mildly reduced the total elongation and tensile strength. An increase in hydrogen content from 12 to $15 \mathrm{ppm}$ had little further effect on the mechanical properties. It was concluded that the transition itself was not due to hydrogen embrittlement, but that it was sensitive to residual strain, strain rate, hydrogen content, and to a smaller extent to heat treatment.

\section{EXPERTMEINTAL PROCEDURE AND RESULTS}

The 1-inch gauge length specimens used in this investigation are shown in Figure K-6A543I. These specimens were machined from a 1-1/2-inch diameter rod with the axis of the specimen parallel to the axis of the rod. The rod had previously been alpha-rolled from biscuit uranium, heated into the betaphase, and quenched. This treatment yields a moderately fine grain size and greatly reduces the preferred orientation of the original rod. The uranium was not analyzed for impurities but a typical analysis for the grade of uranium used is given in section $I$.

Heat treatment of the specimens was performed in a quartz tube which was heated by a resistance furnace. Vacuum was maintained with a mercury diffusion pump and a liquid nitrogen trap. Hydrogen was supplied by diffusion through a palladium tube. At the end of the heating period, the samples were cooled rapidly by a stream of helium through the quartz tube so as to minimize loss of hydrogen. 

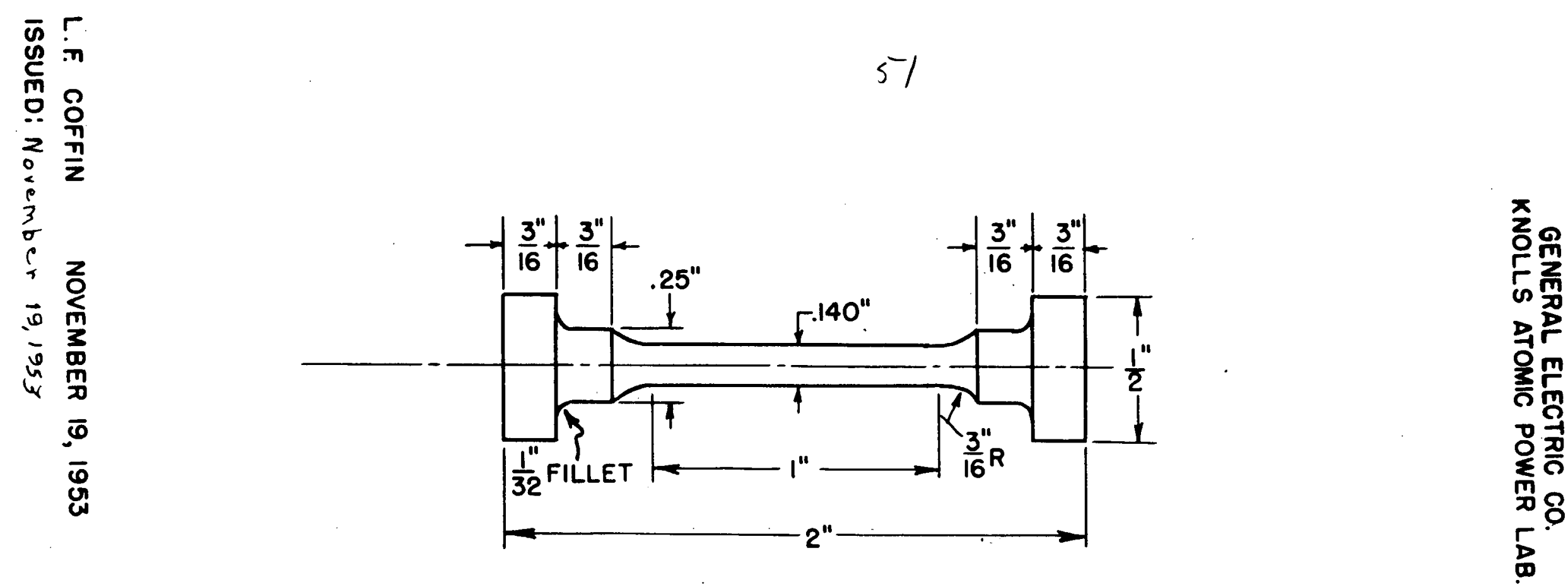

市
0
0
$\dot{0}$
$\frac{1}{3}$

TRANSVERSE SPECIMEN CYCLE STRAIN TEST 
Photomicrographs of the grain structure of the as-received and heattreated uranium are shown in KS-9193. Except for some grain enlargement at $700^{\circ} \mathrm{C}$, no gross changes are evident.

Microscopic examination of broken tensile specimens that showed little elongation often revealed intergranular-type cracks in the strained region. However, no evidence of a film or precipitate at the grain boundaries was ever found.

\section{DISCUSSION}

The results of this investigation may be summarized as follows:

(1) The ductility of hydrogen-free uranium, as measured by elongation, undergoes a transition with temperature. For beta-quenched, alpha-annealed uranium, the transition temperature (temperature at which the elongation is the average of the two extremes) is approximately $-10^{\circ} \mathrm{C}$, and for betaannealed uranium, about $+15^{\circ} \mathrm{C}$.

(2) Addition of up to $0.2 \mathrm{ppm}$ of hydrogen has little effect on the ductility. However, between 0.2 and $0.4 \mathrm{ppm}$, the ductility decreases rapidly. Concentrations greater than $0.4 \mathrm{ppm}$ have no further effect on the ductility. Neither the temperature at which the hydrogen is added nor the temperature of the tensile test appears to have any appreciable effect upon these critical concentrations.

(3) The addition of hydrogen (in excess of $0.4 \mathrm{ppm}$ ) increases the transition temperature about $55^{\circ} \mathrm{C}$ for alpha-annealed uranium and about $30^{\circ} \mathrm{C}$ for beta-annealed uranium. Thus, the transition temperature for hydrogenated uranium is about $45^{\circ} \mathrm{C}$ for both heat treatments. BMI found similar but less pronounced variations in ductility with hydrogen content, and also found higher transition temperatures for both hydrogen-free and hydrogenated uranium.

(4) Both alpha and beta vacuum-annealed uranium have a maximum tensile strength at about $20^{\circ} \mathrm{C}$. Addition of hydrogen lowers the tensile strength and shifts the maximum point about $20^{\circ} \mathrm{C}$ higher.

In view of the unsatisfactory state of the theory of ductility transitions in metals, any explanation of these results will have to await a more comprehensive and detailed study of the uranium-hydrogen system in particular, and of transition phenomena in general.

The fact that the solubility of hydrogen in this uranium exhibits an anomaly in the same range of 0.2 to $0.4 \mathrm{ppm}$ may be more than a coincidence. The steep slope of the initial part of the solubility curve is believed to be caused by absorption of hydrogen by an impurity in the metal, and normal solution in the uranium occurs only after saturation of the small quantity of impurity. If the decrease in ductility is caused only by normal solution of hydrogen in uranium, the observed induction period of about 0.2 ppm would result. 
Figure KS-9186 shows the effect of hydrogen on the experimental stressstrain curve at normal room temperature. All three samples were heated at $600^{\circ} \mathrm{C}$ for 1 hour. These curves illustrate the fact that hydrogen has only a small influence on the stress-strain curve up to the point of fracture, but that fracture occurs at much lower elongations for hydrogenated uranium than it does for hydrogen-free uranium.

It will also be noticed in KS-9186 that the greater part of the decrease in ductility occurs at hydrogen concentrations lower than that given by $4 \mathrm{~mm}$ of hydrogen pressure $(0.3 \mathrm{ppm})$. To determine the relationship, between hydrogen concentration and ductility, tensile specimens were treated at either 600 or $700^{\circ} \mathrm{C}$ for 1 hour at various hydrogen pressures.

The quenching procedure used allows some of the hydrogen to diffuse out of the specimen, but as the loss is probably less than 10\%, the hydrogen concentration was assumed to be that for equilibrium solubility (see Section I). Analyses of some of the broken tensile specimens showed that the average concentration in the specimen, within the experimental error, was that to be expected for equilibrium solubility. (See KS-8988, p. 25.) The concentration in the test section itself, however, is probably somewhat less because of the relatively greater amount of diffusion from the small diameter midale section as compared with the thicker ends.

The results obtained are shown in Figures KS-9189 and -9190 . The change from ductile to relatively brittle metal appears to occur rather abruptly between 0.2 and $0.4 \mathrm{ppm}$, and concentrations higher than this amount have little or no effect. The ultimate tensile strength shows a similar behavior, decreasing from about 113,000 psi to $87,000 \mathrm{psi}$ at room temperature for the alpha-annealed specimens as the hydrogen content increases.

The effect of test temperature on the ductility of hydrogen-free uranium and uranium saturated with hydrogen was determined in the range -30 to $100^{\circ} \mathrm{C}$. The specimens were heat-treated in hydrogen or vacuum at both 600 and $700^{\circ} \mathrm{C}$. The results shown in Figures KS-9I9I and -9192 confirm the presence of a tensile transition in uranium as reported by BMI. For comparison purposes, the BMI results are also shown in these figures. The chief disagreement in the results appears to be that Battelle finds. less difference between hydrogenated and hydrogen-free uranium. This may be because of a less thorough removal of hydrogen from BMI's vacuum-treated specimens (hydrogen content reported by BMI as $0.3 \mathrm{ppm}$ which is too high to be in the ductile region), or possibly the smaller grain size of the "as-received" material which was used at BMI.

Tensile tests of the "as-received" material showed very little difference in behavior from those specimens annealed at $600^{\circ} \mathrm{C}$ in 1 atmosphere of hydrogen. This was to be expected, since the "as-received" material contained I to $2 \mathrm{ppm}$ of hydrogen and had been annealed during the beta-quenching process. 


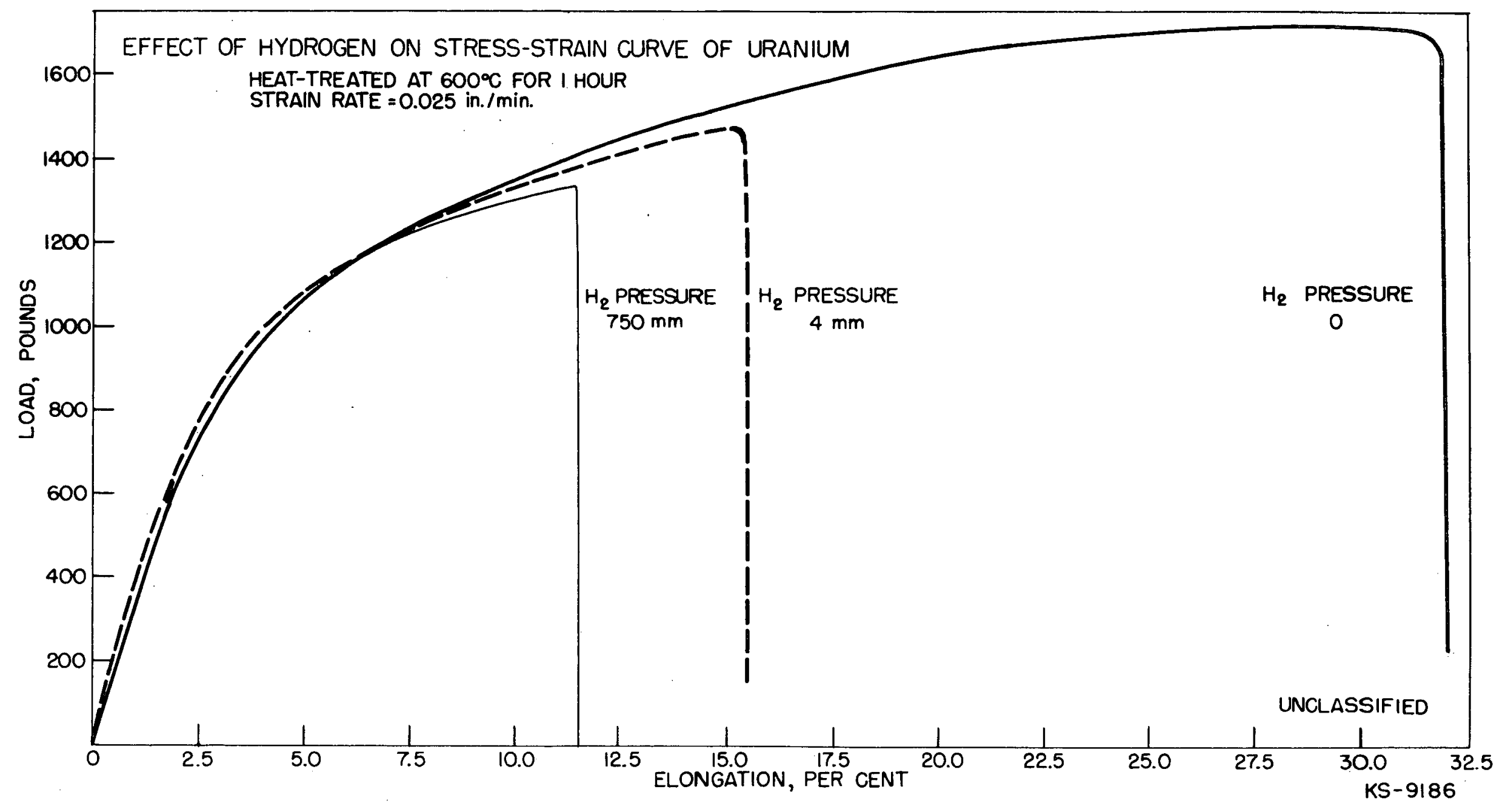




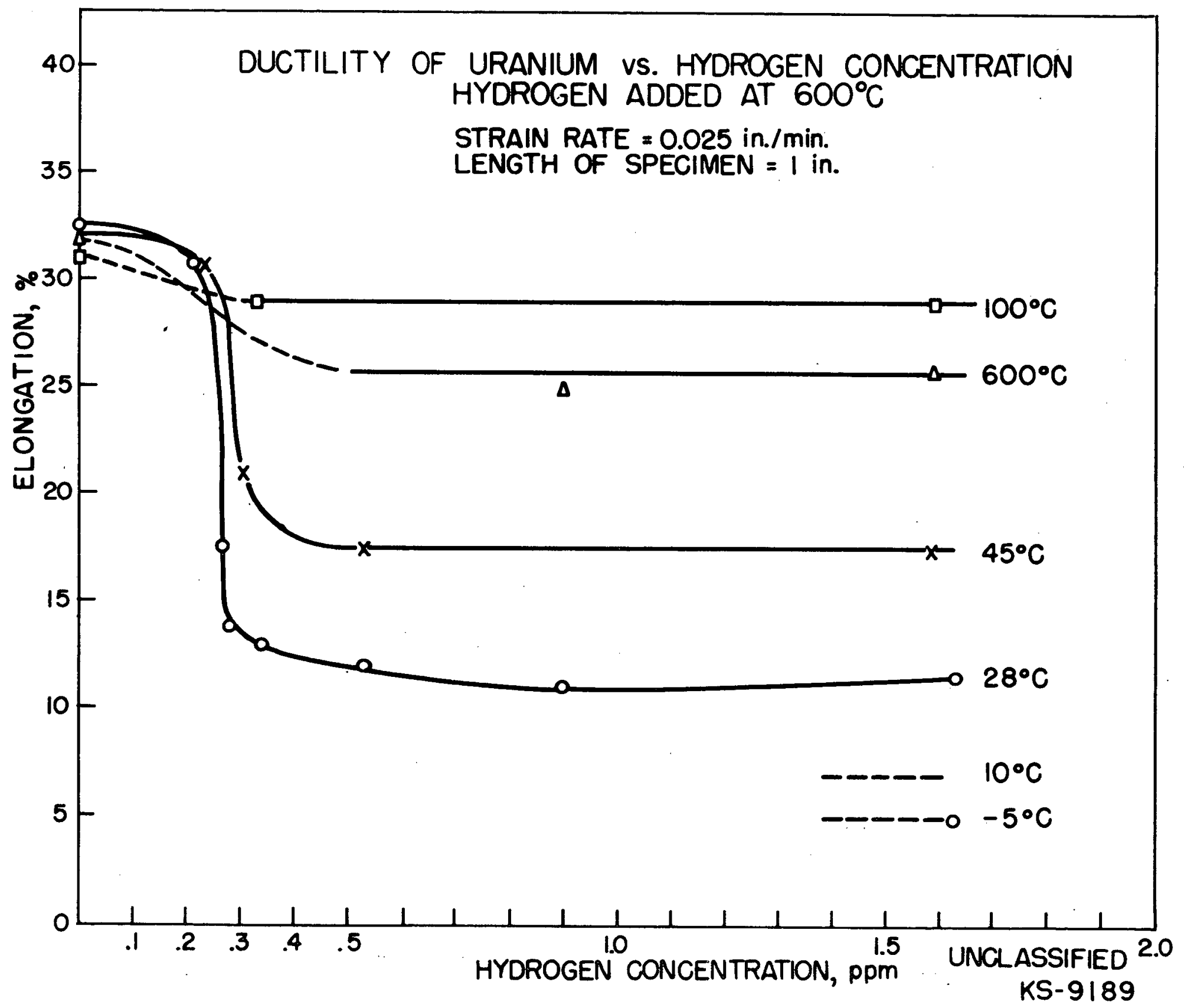








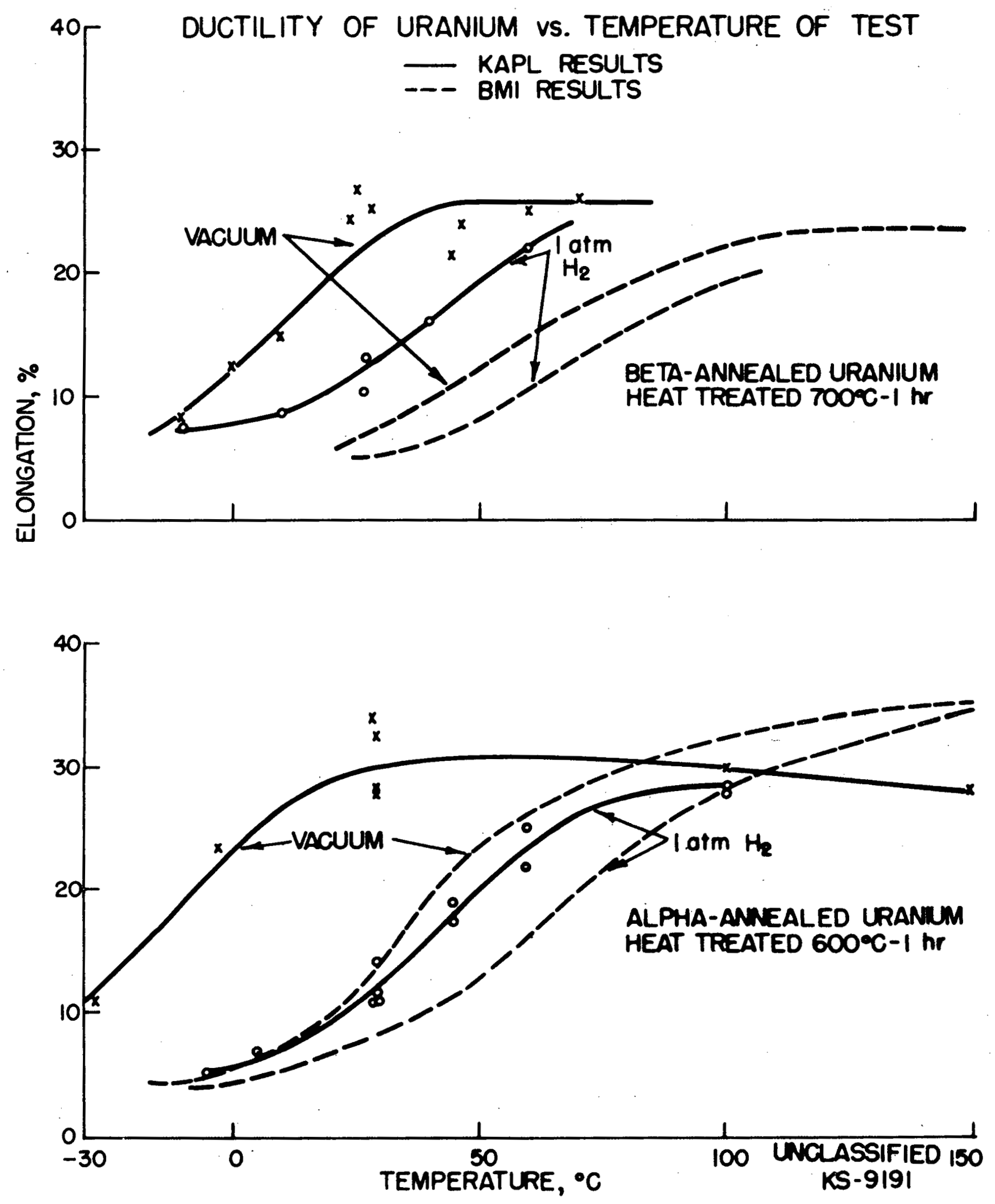


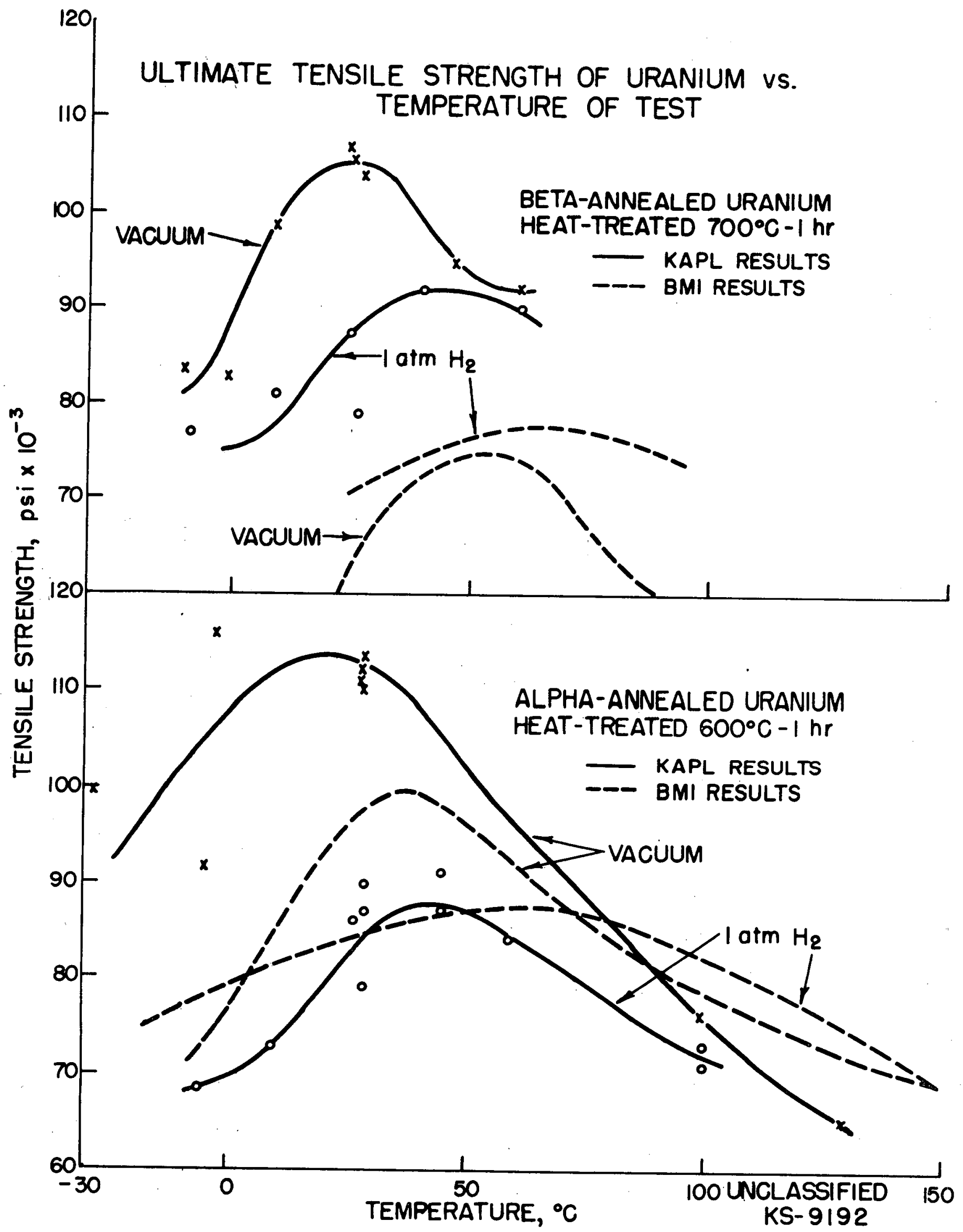




\section{5}

GRATN STRUCIURE OF URANIUM SPECTMANS

$100 x$



No Recelved:

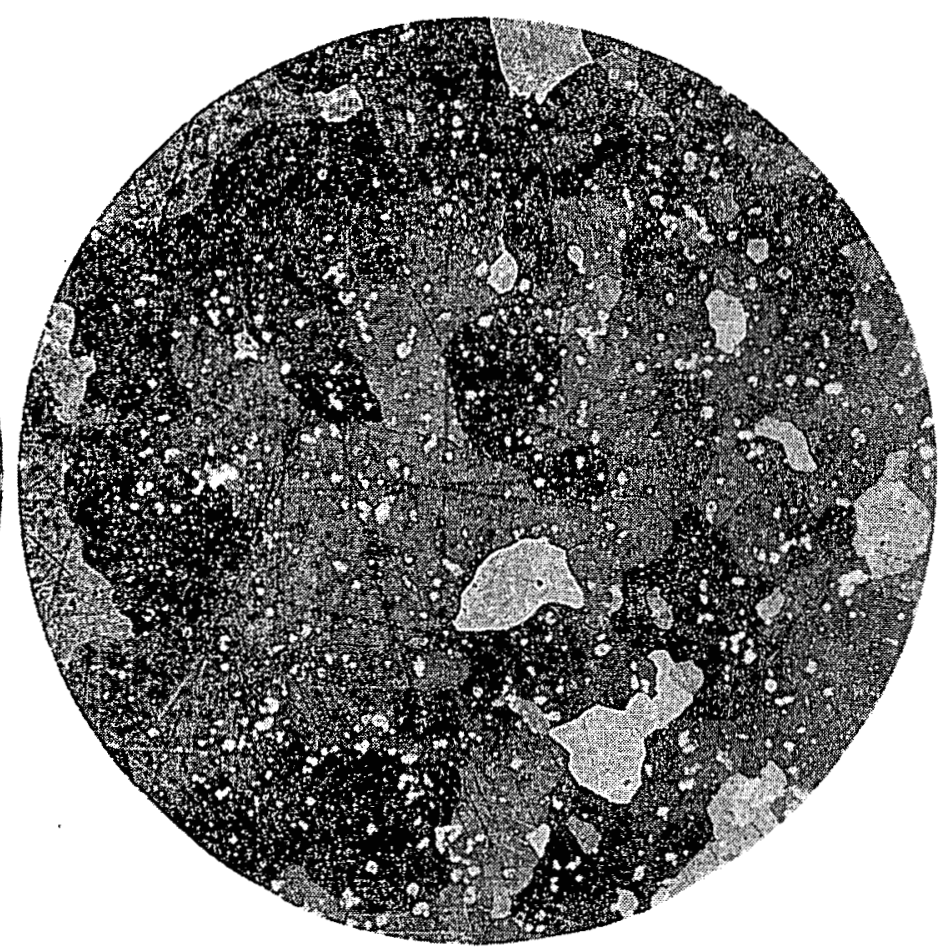

After $600^{\circ} \mathrm{C}$ hr

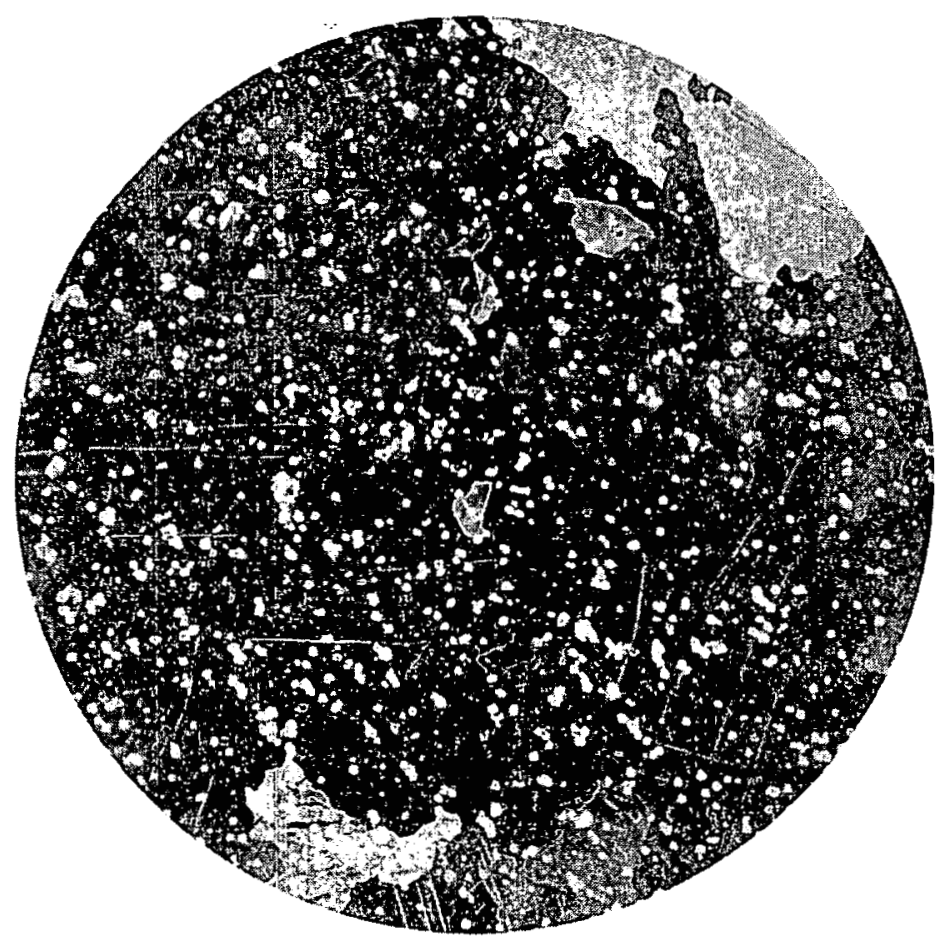

After $700^{\circ} \mathrm{C}-1 \mathrm{hr}$ 
However, the assumption that the decrease in ductility is caused by a hydriding of the impurity concentrated at the grain boundaries would explain the saturation effect found for concentrations above $0.4 \mathrm{ppm}$.

Another possible source of weakness is the formation of a film of uranium hydride at the grain boundaries. Extrapolation of the hightemperature values for the solubility of hydrogen and dissociation pressures of $\mathrm{UH}_{3}$ indicates that most of the hydrogen in uranium at room temperature should be in the form of the hydride. Rees and Hopkins* found that oxygen in iron increases the transition temperature, and personnel at BMI found a similar effect of oxygen in molybdenum.** For molybdenum, oxygen concentrations above $10 \mathrm{ppm}$ have little further effect. Wulff*** and co-workers showed that the oxygen forms a continuous film around the grain boundary causing an intergranular type of failure.

One method of attack to explain these phenomena would be to study the relationship, if any, between the amount of hydride-forming impurities (such as calcium, vanadium, zirconium, niobium, etc.) and the effect of hydrogen on the ductility of uranium. With sufficiently pure uranium, the solubility anomaly vanishes but no information on the mechanical properties of this grade of uranium was obtained.

\footnotetext{
*Rees, W. P., Hopkins, B. E., and Tipler, H. R., J. Iron Steel Inst. 169, (1951); Rees, W. P., and Hopkins, B. E., J. Iron Steel Inst. 172, 403 (1952).

**BMI Report, "Metallurgical Study of Molybdenum, Twelfth Quarterly Status Report," March 1 to May 31, 1952.

***Wulff, J., Shaler, A., Johnston, J., Wong, J., and Moffatt, W., 'Research and Development of Molybdenum Welding," Final Report, April 30, 1951 October 23, 1952, to Flight Research Laboratory, Wright-Patterson Air Force Base.
} 